\title{
TRÁFICO Y MOVILIDAD CARAVANERA EN LA PUNA CATAMARQUEÑA. UNA MIRADA INTERNODAL
}

\author{
CARAVAN TRAFFIC AND MOBILITY IN THE HIGHLANDS OF \\ CATAMARCA. AN INTERNODAL PERSPECTIVE
}

Alvaro Martel', Diego Zamora ${ }^{2}$ y Matías Lépori ${ }^{3}$

\begin{abstract}
Resumen
En el presente trabajo abordamos la problemática de las interacciones sociales entre los grupos que habitaron los nodos de Antofagasta de la Sierra (puna de Catamarca) y de las áreas valliserranas vecinas, durante los Períodos Formativo y de Desarrollos Regionales de la secuencia arqueológica local. Para tal fin, aplicamos la perspectiva metodológica de la arqueología internodal, lo que posibilitó el registro de las antiguas vías de circulación que permitieron el tráfico y la circulación de personas, bienes y animales entre las áreas mencionadas. Hacia el final del trabajo realizamos un análisis integrado de la evidencia recuperada en los internodos, contrastando esta nueva información con los modelos de interacción social propuestos anteriormente desde los registros arqueológicos nodales.
\end{abstract}

Palabras claves: Puna argentina - tráfico caravanero Períodos Formativo y de Desarrollos Regionales.

\begin{abstract}
In this paper we address the issue of social interactions between human groups that inhabited the nodes of Antofagasta de la Sierra (puna of Catamarca) and of the neighboring valleys, during the Formative and Late periods of the local archaeological sequence. For that purpose, we applied the methodological perspective of internodal archaeology, which made possible to register the old caravan tracks that allowed traffic and movement of persons, goods and animals among the aforementioned areas. At the end of the paper we carry out an integrated analysis of the evidence recovered at the internodes, discussing this new information from the nodal archaeological records in relation to previously proposed social interaction models.
\end{abstract}

Keywords: Argentinean Puna - caravan trafficFormative and Late periods.

Recibido: marzo 2016. Aceptado: diciembre 2016.

\section{$*$ Introducción}

La arqueología de la puna argentina se caracterizó, ya desde las primeras expediciones e investigaciones (p.e. Ambrosetti 1904, Boman 1991 [1908], Weisser 1923), por la presencia de materiales y bienes que provenían de regiones alejadas, o bien, de zonas ecológicamente contrastantes. Particularmente, en Antofagasta de la Sierra (puna catamarqueña), este hecho atrajo la atención de diversos investigadores quienes, desde distintas líneas de evidencia y marcos teóricos, buscaron explicar la presencia de tales ítems a partir de diferentes procesos de interacción que, en última instancia, terminaban ajustándose a modelos del tipo de control vertical de pisos ecológicos (Raffino y Cigliano 1973), de complementariedad ecológica de recursos y/o de consolidación de vínculos sociales intercomunitarios, estos dos últimos los mayormente aceptados hasta nuestros días (Aschero 2010, Escola et al. 2015).

La continuidad de las investigaciones arqueológicas en Antofagasta de la Sierra (en adelante ANS), puso de manifiesto que, en términos generales, el acceso a bienes y recursos foráneos por parte de las comunidades locales, no habría tenido un carácter de excepcionalidad sino, por el contrario, se habría mantenido con una notable regularidad desde momentos arcaicos (Rodríguez 1999, 2005; Rodríguez y Martínez 2001; Aschero et al. 2002;

1 ISES, CONICET. Instituto de Arqueología y Museo, Universidad Nacional de Tucumán, ARGENTINA. Email:martelalvaro@gmail.com

2 Instituto de Arqueología y Museo, Universidad Nacional de Tucumán, ARGENTINA. Email:dzamoranasca@gmail.com

3 Becario CIUNT. Instituto de Arqueología y Museo, Universidad Nacional de Tucumán, ARGENTINA. Email:matu_lepori@hotmail.com 
Rodríguez y Aschero 2005; Olivera 2006; Somonte y Cohen 2006; Escola 2007; Martínez et al. 2007; López Campeny 2008, 2010; Babot 2009; López Campeny et al. 2014, entre otros).

No es nuestra intención abordar los procesos de interacción e intercambio pre-formativos en ANS. Sin embargo, siguiendo las propuestas de Aschero (2007), asumimos como argumento de partida del presente trabajo, que es durante el Arcaico cuando se fundan las bases de una red de interacción social que determinará -en parte- los procesos culturales posteriores en la región.

Ahora bien, este cúmulo de evidencias vinculadas a las interacciones sociales post-arcaicas, recuperadas en estratigrafía en diferentes sitios de ANS y asociadas a contextos diversos (domésticos, rituales, funerarios, etc.), encontraban aún mayor respaldo en una significativa profusión de un arte rupestre caravanero, plenamente vigente desde momentos formativos (Martel 2010), que se emplazaba próximo a -o directamente en- los mismos sitios de los cuales se obtenían estos objetos y/o recursos de origen distante. Tales asociaciones contextuales permitieron, lógicamente, considerar el tráfico caravanero como uno de los mecanismos de peso para la consecución de aquellos procesos de interacción social que implicaron el desplazamiento y circulación de bienes y personas, entre ANS y regiones vecinas.

Sin embargo, cabe destacar que toda esta información y evidencia contextual asociada a situaciones de contactos, intercambios e interacciones a mediana y larga distancia, fue obtenida a partir de investigaciones de escala microrregional (sensu Aschero 1988), lo cual, desde la perspectiva de una arqueología internodal (Berenguer y Pimentel 2010; Nielsen 2006, 2011), restringía las posibilidades de interpretación de tales datos dado el carácter de espacio nodal de ANS (Martel 2014). De este modo, se nos presentaban numerosos interrogantes respecto de la naturaleza de los diversos mecanismos de interacción y sus características materiales, los cuales -necesariamentedebíamos buscar en aquellos espacios donde las diferentes prácticas de movilidad tuvieron lugar.

En el presente trabajo, presentamos un conjunto de evidencias vinculado a procesos de interacción social, recuperado en contextos de tráfico caravanero, en el espacio internodal que media entre ANS y los valles cata- marqueños de Hualfín, Belén y Fiambalá. Para finalizar, integraremos dicha información con la disponible para el internodo del volcán Galán, entre ANS y el valle Calchaquí medio (Martel 2014), con el fin de elaborar una propuesta preliminar sobre la red vial que permitió la conexión entre estos diferentes espacios nodales. Cabe aclarar que cuando decimos 'red vial' no estamos pensando en un sistema formal y estructurado de caminos como el alcanzado en tiempos del Inka con el Qhapac Ñan, sino, más bien, lo pensamos en los términos propuestos por Pimentel (2013:3), como el contexto agencial de los viajeros, lo tangible y concreto de las prácticas de movilidad en los espacios internodales.

\section{* GeOgrafía de LA INTERACCIÓN Y SUS EVIDENCIAS}

La microrregión de Antofagasta de la Sierra se encuentra emplazada en el extremo meridional de la puna argentina, en la porción norte de la provincia de Catamarca. Ambientalmente se define como un desierto de altura donde, sin embargo, la cuenca endorreica del río Punilla favoreció la concentración de recursos vegetales y animales que permitieron la continuidad de la ocupación humana a lo largo de los últimos 10 mil años (Aschero 2010).

La ubicación geográfica de ANS, en términos de redes de interacción, le otorga un carácter fundamental como punto de origen, destino y articulación de rutas (Figura 1). Su posición resulta estratégica respecto de las principales regiones valliserranas, ya que en un radio promedio de $150 \mathrm{~km}$-con ANS como centro- se alcanzan, hacia el sur, los valles de Fiambalá/Abaucán, Hualfín, Belén y Yocavil (Catamarca); hacia el este, los valles Calchaquíes (Salta); y, hacia el norte, los salares de la puna central (Salta). Hacia el oeste, en el mismo rango de distancia, se alcanzan desde ANS los sectores altos de las cuencas del río Copiapó y Quebrada del Salado, ya sobre la vertiente occidental de la cordillera de los Andes en el ámbito de la región de Atacama. Si bien en este trabajo no abordaremos los derroteros hacia esta región trasandina, cabe destacar que en ANS - sitio Punta de la Peña 13, quebrada del río Las Pitas- se realizó el hallazgo de un fragmento de cerámica Diaguita Inka, asociado a un panel con pinturas rupestres donde registramos un motivo de caravana que asignamos - según criterios estilísticos- a momentos finales del Período de Desarrollos Regionales (en adelante PDR), o bien, Inka (Martel 2010), estable- 


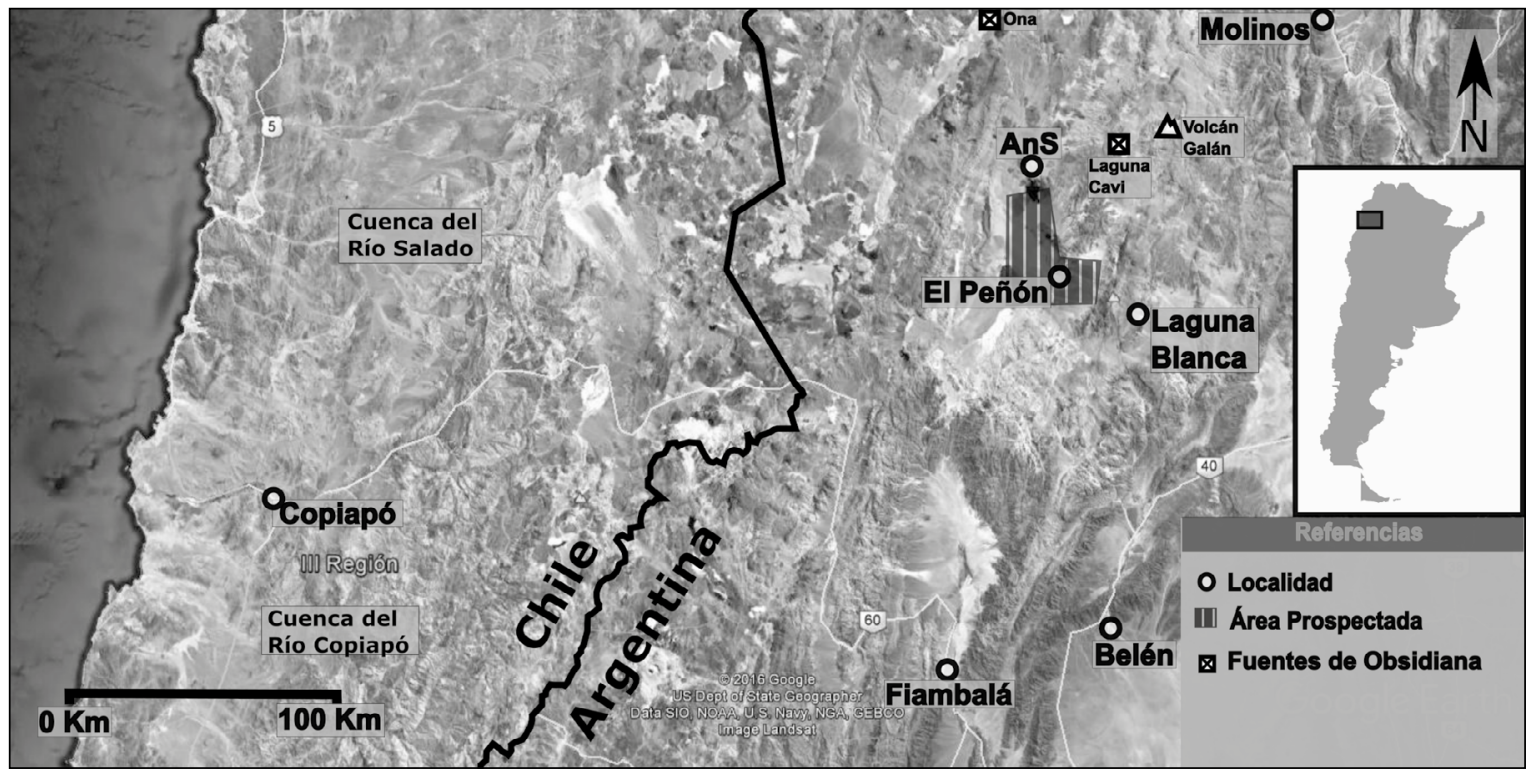

Figura 1. Ubicación de Antofagasta de la Sierra en relación a las áreas nodales valliserranas.

ciendo así un argumento de peso para futuras investigaciones que den cuenta de las vías de tránsito entre estos espacios nodales.

Volviendo al caso que nos ocupa, esta proximidad geográfica entre ANS y los nodos valliserranos también fue una proximidad social, la cual tiene su expresión material más directa en numerosos contextos arqueológicos de la microrregión y a lo largo de toda la secuencia de ocupación. Tal como mencionáramos anteriormente, las evidencias de interacción están dadas por la presencia de recursos y bienes foráneos, o también por manufacturas locales pero realizadas sobre materias primas alóctonas. Dentro de este conjunto de evidencias, particularmente para los Períodos Formativo y PDR, la cerámica decorada fue considerada comúnmente como el indicador más directo de tales interacciones.

La mayor frecuencia, en ANS, de estilos cerámicos identificados como Ciénaga, Aguada y Belén, llevó a diversos investigadores a considerar que las interacciones con las comunidades de los valles catamarqueños referidos, donde estos estilos cerámicos tendrían su origen, fueron determinantes en los procesos sociales locales (Raffino y Cigliano 1973; Olivera 1992; Podestá y Olivera 2006, Olivera et al. 2008; Salminci 2015, entre otros). Sin embargo, es preciso destacar que en los últimos años la información arqueológica proveniente de diversos sitios del bolsón de Laguna Blanca -ubicado en el borde de puna meridional, a unos $70 \mathrm{~km}$ hacia el SE de ANS y asociado a una de las principales vías de circulación hacia los valles-, permitió identificar una tradición alfarera local, la cual discute y aporta numerosos argumentos para la revisión de las propuestas tradicionales respecto de la circulación de objetos cerámicos durante el primer milenio de la era en la región (Espiro 2008, 2012, entre otros), como así también, obliga a una reconsideración del rol de Laguna Blanca en el desarrollo de los procesos de interacción. Más adelante volveremos sobre este punto.

Por su parte, como destacáramos más arriba, el arte rupestre de ANS muestra ya desde momentos formativos una significativa presencia de motivos de caravanas de llamas (Aschero 2000; Martel y Aschero 2007; Martel 2010, entre otros) (Figura 2). Estas representaciones particulares se distribuyen, principalmente, en los sectores de fondo de cuenca y parte media de las quebradas subsidiarias, que son los espacios que cuentan con mayor registro de asentamientos permanentes (bases residenciales, conjuntos habitacionales), o bien, temporales (puestos agropastoriles). Esto resulta en una singularidad contextual, ya que los registros arqueológicos de los sitios donde se emplazan las representaciones de caravanas, por lo general, dan cuenta de prácticas distintas a las aludidas por estos motivos rupestres. 


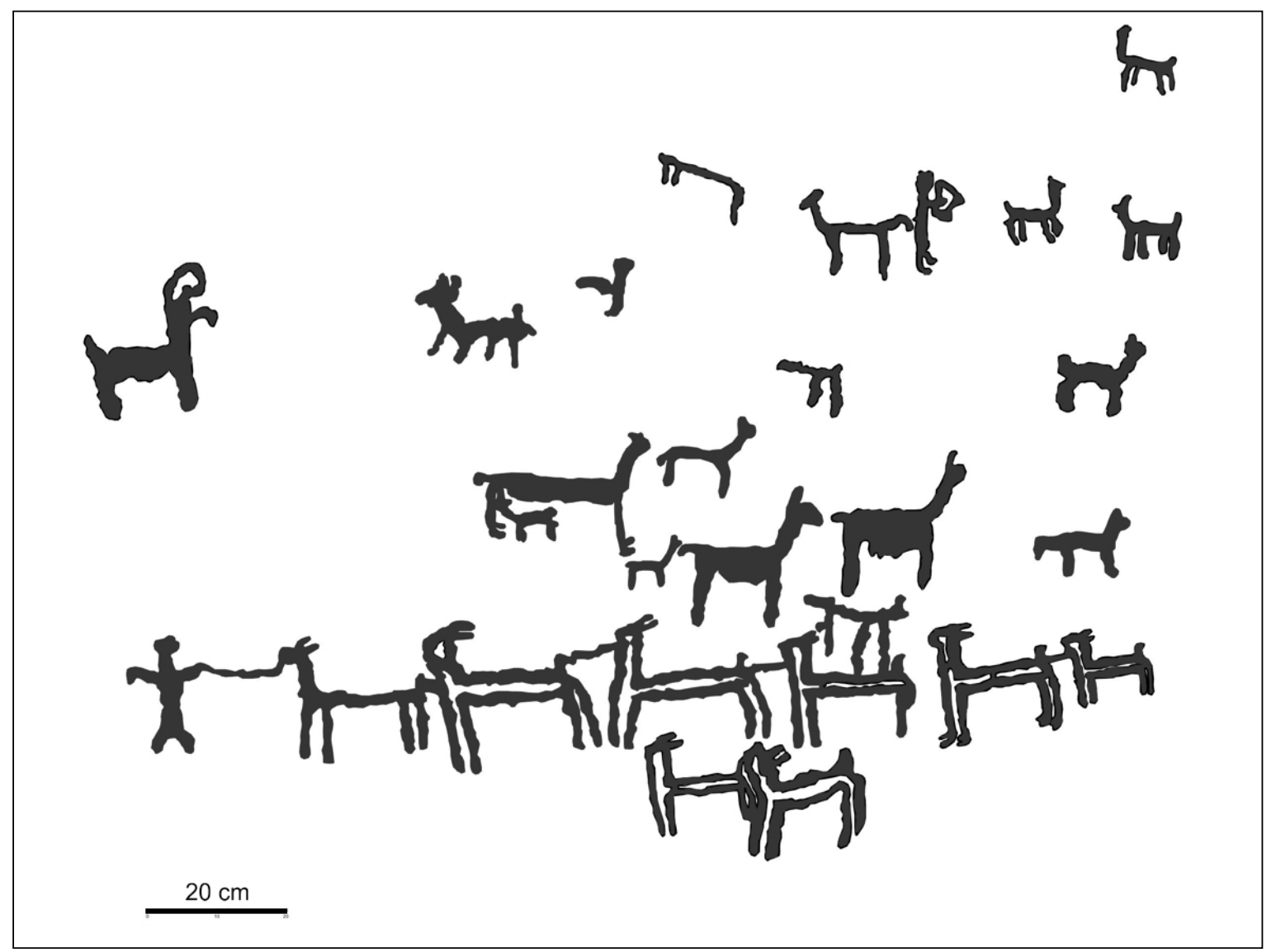

Figura 2. Grabados del sitio Peñas Coloradas 2.4, quebrada de Las Pitas, Antofagasta de la Sierra. Motivo de caravana con antropomorfo guía correspondiente a la modalidad estilística Punta del Pueblo (500-1000 d.C.) y representaciones de camélidos y antropomorfos de modalidades posteriores. Digitalización del calco, Romina García.

Tal situación contextual admite, al menos, dos interpretaciones posibles que se sustentan principalmente desde la información etnoarqueológica (Nielsen 1997-1988, 2000): 1) dado el carácter esporádico de las prácticas de tráfico, los contextos producidos habrían sido fácilmente obliterados por la realización de otras prácticas más frecuentes, quedando solo como evidencia los motivos rupestres; 2) las representaciones de caravanas fueron realizadas en el marco de actividades (ceremonias pre o post-realización del viaje) asociadas al tráfico caravanero pero no necesariamente en un contexto de tráfico.

La primera interpretación presupone a viajeros no locales como los circunstanciales autores de las representaciones, los cuales habrían ocupado de forma temporaria la infraestructura disponible (corrales, puestos). La segunda, asume como autores a los habitantes locales que, en determinados momentos del año, desde sus propios lugares de habita- ción, habrían dado lugar a una serie de prácticas específicas vinculadas a los preparativos del viaje, desde lo meramente logístico (preparación de animales, carga, equipo personal y arreos, etc.) hasta lo ceremonial (p.e. actualización del diálogo con deidades y antepasados para procurar la protección durante el viaje y el éxito del intercambio, rogativas por la salud y bienestar de animales y viajeros, etc.). Mientras no dispongamos de otros argumentos contextuales, preferimos inclinarnos hacia la segunda interpretación, ya que encuentra mayor respaldo en el registro material. Sin embargo, desde una perspectiva espacial, el emplazamiento de este arte rupestre en quebradas que forman corredores naturales (Las Pitas, Miriguaca, Curuto, Calalaste), no nos permite desestimar la primera interpretación.

Otro tipo de evidencia asociada frecuentemente a la práctica del caravaneo, comprende los ganchos de atalaje o tarabitas, los que habrían servido -entre otras funcio- 
nes- para ajustar la carga al lomo de la llama. Siguiendo a Raviña et al. (2007), estos objetos, registrados en numerosos sitios del NOA, proceden en su mayoría de la puna y de las principales quebradas de acceso a éstaquebradas de Humahuaca (Jujuy) y del Toro (Salta) - y, en menor medida, de sitios valliserranos. Respecto a la cronología, tal como ocurre también en el área atacameña, habría cierto consenso sobre su adscripciónal PDR con continuidad en el Período Inka y Colonial, dada su frecuente asociación contextual con materiales de estos períodos. Específicamente para ANS, se dio a conocer recientemente un fechado radiocarbónico realizado directamente sobre una tarabita recuperada en un contexto funerario del extenso sitio PDR/Inka de La Alumbrera. Este fechado es el primero que se realiza sobre este tipo de artefactos y se obtuvo una edad de $534 \pm 59$ años AP (Elías et al. 2015), lo cual respalda las adscripciones cronológicas relativas mencionadas anteriormente.

Resumiendo, podemos decir que la información disponible sobre distintos aspectos de los procesos de interacción en ANS presenta un carácter primordialmente nodal. Es decir, podemos abordar problemas referidos al origen de los bienes y recursos foráneos registrados, su valor social y/o económico en el seno de los grupos puneños, la perduración de los vínculos establecidos con comunidades de otras áreas, etcétera. Sin embargo, en términos materiales, lo que observamos en los nodos es el resultado final de tales procesos de interacción, lo cual no ofrece las mejores condiciones, tal como sostiene Nielsen (2006), para aportar información sustancial acerca los mecanismos que permitieron la interacción interregional ni del marco histórico-procesual en la que tuvo lugar.

A continuación, presentamos los resultados de los trabajos que venimos realizando en las amplias planicies de Carachipampa y El Peñón, emplazadas al sur y suroeste de ANS, y que se constituyen en espacios internodales que -tanto en el pasado como en la actualidad- deben ser atravesados para alcanzar los pasos que permiten acceder a los nodos de borde de puna (Laguna Blanca) y valliserranos. Nuestro objetivo principal es recuperar información sobre los aspectos materiales de las vías de tránsito y las prácticas sociales vinculadas al tráfico interregional, con el fin de lograr mayores detalles sobre los procesos de interacción en ANS.

\section{$*$ Resultados}

\section{El Peñón}

Iniciamos los trabajos prospectivos en la localidad de Peñas Chicas del Peñón (en adelante PChP, 3420 msnm, S $26^{\circ} 31^{\prime} 09,02^{\prime \prime} ;$ O $\left.67^{\circ} 15^{\prime} 48,73^{\prime \prime}\right)$, ubicada a $4 \mathrm{~km}$ al sur del actual pueblo de El Peñón y a $50 \mathrm{~km}$ al sur-sureste de la villa de ANS (Departamento Antofagasta de la Sierra, Catamarca). En este sector, a partir del análisis previo de imágenes satelitales, habíamos podido detectar ciertas marcas en el terreno que por su morfología nos indicaban un posible origen antrópico.

Ya en el terreno, registramos la presencia de numerosos senderos que conformaban cinco ramales de una vía de circulación principal, a los que denominamos $\mathrm{R}_{1}, \mathrm{R}_{2}, \mathrm{R}_{3}$, R4 y R5; y que, en este sector de PChP, se disponen en forma mayormente paralela con sentido NO-SE, vinculando el sector donde se emplaza actualmente el pueblo de El Peñón (en adelante EP) con el Abra de Pasto Ventura (en adelante APV) (Figura 3). Esta última, representa el paso natural y más transitable hacia la localidad de Laguna Blanca y los valles mesotermales al sur de la puna meridional, principalmente los valles de El Bolsón, Hualfín y Belén. Cabe destacar que PChP comprende una planicie de suelo desnudo y pendiente suave este-oeste, configurando un espacio amplio con pocas opciones de reparo en los $23 \mathrm{~km}$ que separan EP de APV. Estas características topográficas y su casi nula cobertura vegetal permiten una muy buena visibilidad de los rasgos en superficie lo que, sumado a una buena conservación de los senderos, posibilitó recorrerlos durante distancias considerables (Figura 4).

Antes de continuar con la descripción del registro, es preciso aclarar que convenimos en adoptar las definiciones que Pimentel (2013) instrumenta para el análisis de redes viales, donde vía de circulación es el concepto que da cuenta de un trayecto tangible y específico, conformado por caminos y/o senderos. Los caminos constituyen vías formalizadas que evidencian algún tipo de trabajo de construcción y mantenimiento, mientras que los senderos comprenden vías informales producidas por el simple tránsito recurrente de personas o animales, que no presentan trabajo de construcción ni mantenimiento. 


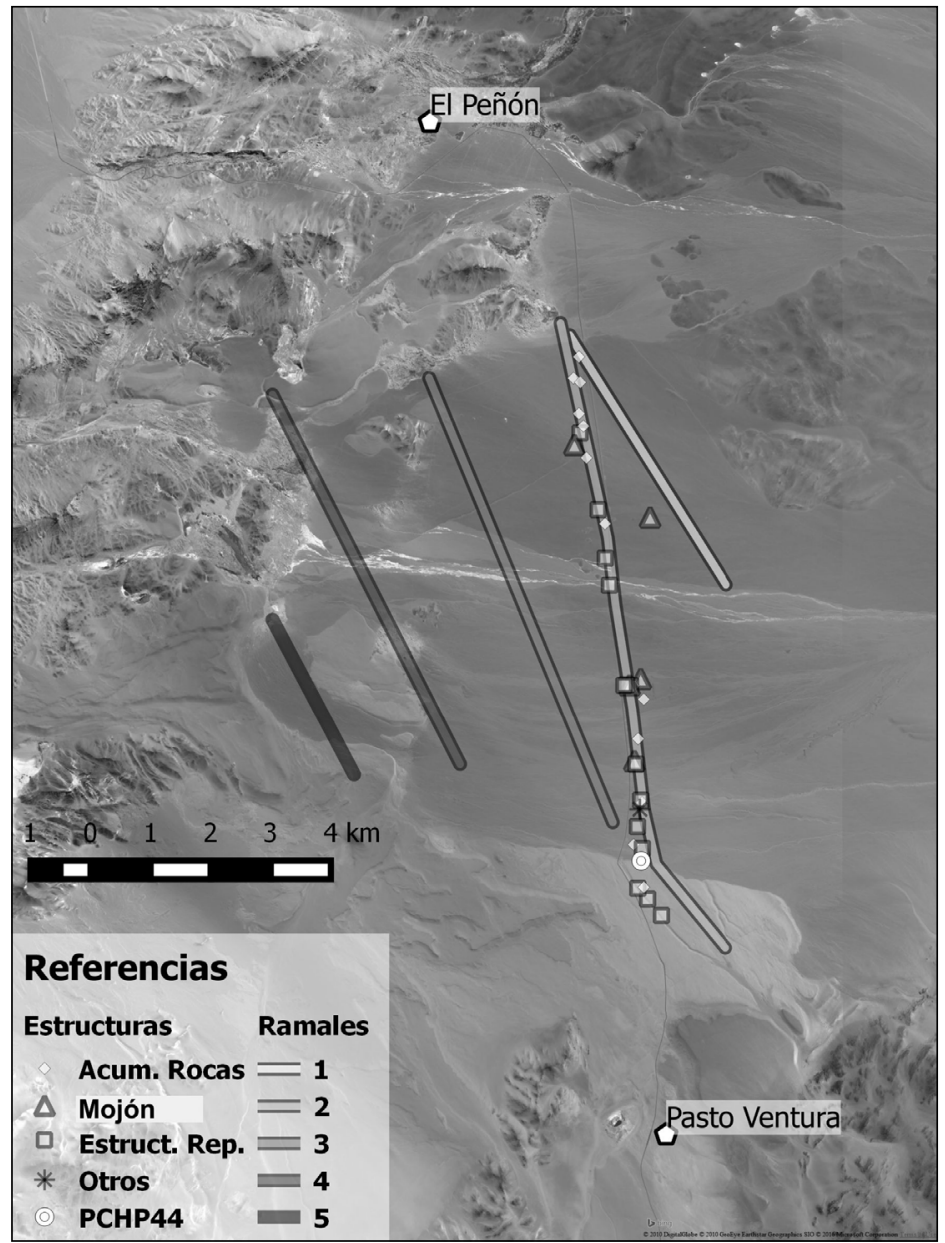

Figura 3. Distribución de sitios asociados a la vía de circulación entre El Peñón y el Abra de Pasto Ventura.

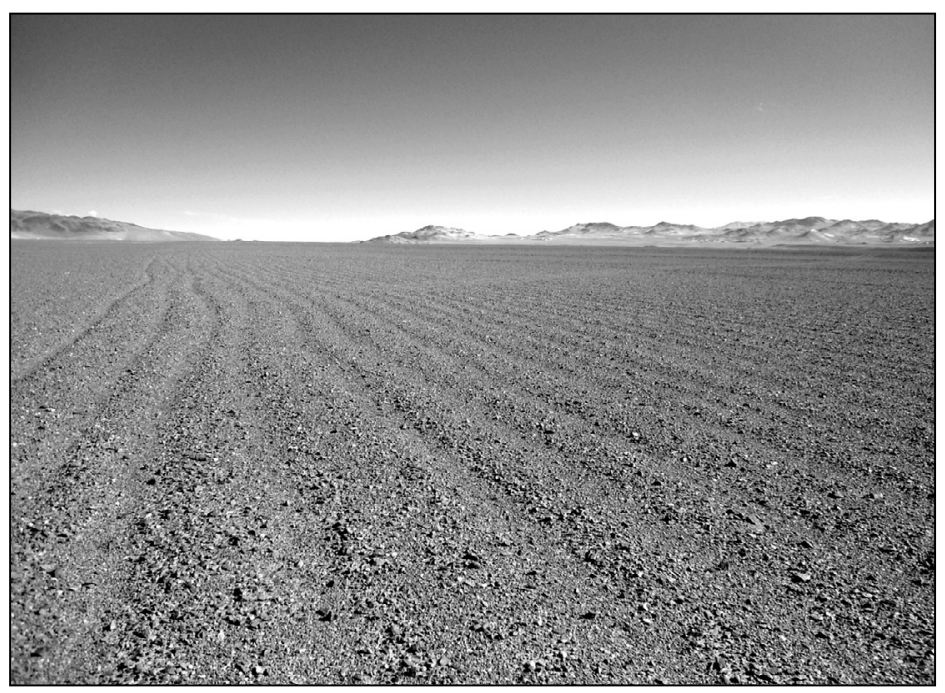

Figura 4. Senderos en la planicie de Peñas Chicas del Peñón. Al fondo, Abra de Pasto Ventura. 
A su vez, tomamos también de este mismo autor algunas consideraciones sobre la morfología de los senderos, las cuales pueden ser útiles para apreciaciones cronológicas relativas. Sostiene Pimentel (2013) que, en el área atacameña, es frecuente el registro de dos tipos de patrones en la disposición de los senderos: entrelazados y paralelos. Mientras que en el primero los senderos son sinuosos y con una alta frecuencia de superposiciones debido a la marcha no lineal de las llamas cuando transitan espacios abiertos, el segundo se compone de senderos más bien rectos con un desarrollo paralelo entre ellos, producto de la marcha más rectilínea de los equinos. Tal clasificación, sin ser excluyente ni definitoria, resulta operativa en una instancia inicial de la investigación, ya que permite una diferenciación preliminar entre vías caravaneras prehispánicas y vías troperas históricas.

A continuación presentamos información general de cada uno de los ramales registrados (Tabla 1). Nos centraremos en el análisis de R2 ya que cuenta con la mayor variedad y variabilidad de evidencia material, lo cual nos permitirá evaluar -con mayor profundidad temporal- diversos aspectos del tráfico caravanero en este internodo.

Acumulaciones de rocas. A lo largo de los $12 \mathrm{~km}$ de recorrido, registramos 51 estructuras directamente asociadas a los senderos (Tabla 2, Gráfico 1). De éstas, 26 comprenden acumulaciones de rocas que, en general, presentan características similares: planta circular a subcircular, 1,5 $\mathrm{m}$ de diámetro promedio, alturas que no superan los $25 \mathrm{~cm}$ y ausencia de asociaciones materiales en superficie. Se pudieron identificar también otras estructuras de acumulación: cinco mojones (sensu Vitry 2002) de hasta $50 \mathrm{~cm}$ de altura, uno con material histórico asociado -botella de vidrio-, los restantes sin asociaciones materiales,y una acumulación de rocas mayor a la que denominamos montículo, conformado principalmente por rocas grises (esquistos y vulcanitas) pequeñas y medianas sin selección aparente y nódulos medianos de cuarzo blanco (Figura 5).

\begin{tabular}{|c|c|c|c|c|c|c|c|}
\hline Ramal & $\begin{array}{l}\text { Long. } \\
(\mathrm{Km})\end{array}$ & $\begin{array}{l}\text { Coords. } \\
\text { y altura } \\
\text { iniciales }\end{array}$ & $\begin{array}{l}\text { Coords. } \\
\text { y altura } \\
\text { finales }\end{array}$ & $\begin{array}{l}\text { Ancho } \\
\text { (m) }\end{array}$ & $\begin{array}{c}\mathbf{N}^{\circ} \text { de } \\
\text { Senderos }\end{array}$ & $\begin{array}{l}\text { Patrón de } \\
\text { senderos }\end{array}$ & Rasgos asociados \\
\hline $\mathrm{R}_{1}$ & 4,5 & $\begin{array}{c}\mathrm{S}_{2} 6^{\circ} 30^{\prime} 40,42^{\prime \prime} \\
\mathrm{O} 67^{\circ} 15^{\prime} 03,88^{\prime \prime} \\
3462 \mathrm{msnm}\end{array}$ & $\begin{array}{c}\mathrm{S} 26^{\circ} 32^{\prime} 54,75^{\prime \prime} \\
\mathrm{O} 67^{\circ} 13^{\prime} 30,20^{\prime \prime} \\
3663 \mathrm{msnm}\end{array}$ & 25 & 28 & Paralelo & $\begin{array}{l}6 \text { estructuras asociadas directamente } \\
\text { (estructuras de habitación, acumulaciones } \\
\text { de rocas, mojón). Materiales registrados: } \\
\text { fragmentos y botellas de vidrio, latas de } \\
\text { conserva. }\end{array}$ \\
\hline $\mathrm{R}_{2}$ & 10,5 & $\begin{array}{c}\mathrm{S}_{2} 6^{\circ} 30^{\prime} 33,33^{\prime \prime} \\
\mathrm{O} 67^{\circ} 15^{\prime} 10,20^{\prime \prime} \\
3454 \mathrm{msnm}\end{array}$ & $\begin{array}{c}\mathrm{S}_{2} 6^{\circ} 36^{\prime} 09,76^{\prime \prime} \\
\mathrm{O} 67^{\circ} 14^{\prime} 10,72^{\prime \prime} \\
3657 \mathrm{msnm}\end{array}$ & 150 & $>100$ & $\begin{array}{c}\text { Paralelo/ } \\
\text { Entrelazado }\end{array}$ & $\begin{array}{l}51 \text { estructuras directamente asociadas } \\
\text { (acumulaciones de rocas y estructuras de } \\
\text { habitación). Materiales registrados: fragmentos } \\
\text { cerámicos Río Diablo y/o Ciénaga y Belén- } \\
\text { Inka, desechos de talla de vulcanitas y } \\
\text { cuarcitas, fragmentos y botellas de vidrio, latas } \\
\text { de conserva. }\end{array}$ \\
\hline $\mathrm{R}_{3}$ & 7,8 & $\begin{array}{c}\mathrm{S}_{2} 6^{\circ} 31^{\prime} \mathrm{O} 3,15^{\prime \prime} \\
\mathrm{O} 67^{\circ} 16^{\prime} 28,15^{\prime \prime} \\
3373 \mathrm{msnm}\end{array}$ & $\begin{array}{c}\mathrm{S}_{2} 6^{\circ} 35^{\prime} \mathrm{O} 3, \mathrm{O} 6^{\prime \prime} \\
\mathrm{O} 67^{\circ} 14^{\prime} 38,03^{\prime \prime} \\
3553 \mathrm{msnm}\end{array}$ & 8 & 10 & Entrelazado & \multirow{2}{*}{$\begin{array}{l}\text { Estos ramales se identificaron en imagen } \\
\text { satelital. Como no fueron recorridos en su } \\
\text { totalidad en el terreno, definimos puntos } \\
\text { de control sobre los mismos para recabar } \\
\text { información de base. }\end{array}$} \\
\hline $\mathrm{R}_{4}$ & 6 & $\begin{array}{c}\mathrm{S}_{2} 6^{\circ} 31^{\prime} 11,82^{\prime \prime} \\
\mathrm{O} 67^{\circ} 16^{\prime} 28,15^{\prime \prime} \\
3373 \mathrm{msnm}\end{array}$ & $\begin{array}{c}\mathrm{S} 26^{\circ} 34^{\prime} 30,10^{\prime \prime} \\
\mathrm{O} 67^{\circ} 16^{\prime} 10,71^{\prime \prime} \\
3455 \mathrm{msnm}\end{array}$ & 7 & 11 & Entrelazado & \\
\hline $\mathrm{R}_{5}$ & 3 & $\begin{array}{c}\mathrm{S}_{2} 6^{\circ} 33^{\prime} 12,81^{\prime \prime} \\
\mathrm{O} 67^{\circ} 18^{\prime} \mathrm{O} 3,66^{\prime \prime} \\
3286 \mathrm{msnm}\end{array}$ & $\begin{array}{c}\mathrm{S}_{26^{\circ}} 34^{\prime} 36,31^{\prime \prime} \\
\mathrm{O} 67^{\circ} 17^{\prime} 12,92^{\prime \prime} \\
3403 \mathrm{msnm}\end{array}$ & 13 & $\mathrm{~S} / \mathrm{r}$ & Entrelazado & $\begin{array}{l}6 \text { acumulaciones de rocas de tamaño mediano, } \\
\text { planta circular a subcircular de } 1 \text { a 1,5 m de } \\
\text { diámetro y alturas variables entre } 25 \text { y } 30 \mathrm{~cm} \text {. } \\
\text { No se registraron materiales asociados. }\end{array}$ \\
\hline
\end{tabular}

Tabla 1. Características generales de los ramales registrados en la planicie de Peñas Chicas del Peñón. 


\section{Alvaro Martel, Diego Zamora y Matías Lépori}

\begin{tabular}{|c|c|c|}
\hline Sitio & Coordenadas - msnm & Tipo de sitio \\
\hline $\mathrm{PCHP}_{9}$ & $26^{\circ} 30^{\prime} 51.45^{\prime \prime} \mathrm{S}-67^{\circ} 14^{\prime} 58.87^{\prime \prime} \mathrm{O}-3468$ & Acumulación de rocas, $1,4 \mathrm{~m} \times 1,4 \mathrm{~m}$, asociada a senderos paralelos. \\
\hline PCHP15 & $26^{\circ} 31^{\prime} 02.99^{\prime \prime} \mathrm{S}-67^{\circ} 15^{\prime} 02.10^{\prime \prime} \mathrm{O}-3473$ & Acumulación de rocas pequeñas, $1 \mathrm{~m} \times 1 \mathrm{~m}$, asociada a senderos entrelazados/paralelos. \\
\hline $\mathrm{PCHP} 16$ & $26^{\circ} 31^{\prime} 05.24^{\prime \prime} \mathrm{S}-67^{\circ} 14^{\prime} 58.05^{\prime \prime O}-3479$ & Acumulación de rocas pequeñas, $1 \mathrm{~m} \times 1 \mathrm{~m}$, asociada a senderos entrelazados/paralelos. \\
\hline PCHP17 & $26^{\circ} 31^{\prime} 22.13^{\prime \prime} \mathrm{S}-67^{\circ} 14^{\prime} 58.86^{\prime \prime} \mathrm{O}-3490$ & Acumulación de rocas pequeñas, $1 \mathrm{~m} \times 1 \mathrm{~m}$, asociada a senderos entrelazados/paralelos. \\
\hline PCHP18 & $26^{\circ} 31^{\prime} 28.79^{\prime \prime} \mathrm{S}-67^{\circ} 14^{\prime} 56.16^{\prime \prime} \mathrm{O}-3498$ & Acumulación de rocas pequeñas, $1 \mathrm{~m} \times \mathrm{lm}$, asociada a senderos entrelazados/paralelos. \\
\hline PCHPi9 & $26^{\circ} 31^{\prime} 33.83^{\prime \prime} \mathrm{S}-67^{\circ} 14^{\prime} 58.19^{\prime \prime O}-3500$ & Estructura de muro simple semicircular, $1,5 \mathrm{~m} \times 1,5 \mathrm{~m}$, asociada a senderos. \\
\hline $\mathrm{PCHP}_{2} \mathrm{O}$ & $26^{\circ} 31^{\prime} 38.76^{\prime \prime} \mathrm{S}-67^{\circ} 15^{\prime} \mathrm{O} .61^{\prime \prime} \mathrm{O}-3498$ & Mojón asociado a senderos entrelazados/paralelos. \\
\hline $\mathrm{PCHP}_{21}$ & $26^{\circ} 31^{\prime} 45.88^{\prime \prime} \mathrm{S}-67^{\circ} 14^{\prime} 54.32^{\prime \prime} \mathrm{O}-3511$ & Acumulación de rocas pequeñas, $1 \mathrm{~m}$ x 1m, asociada a senderos entrelazados/paralelos. \\
\hline $\mathrm{PCHP}_{22}$ & $26^{\circ} 32^{\prime} 15.20^{\prime \prime} \mathrm{S}-67^{\circ} 144^{\prime} 47.28^{\prime \prime} \mathrm{O}-3528$ & $\begin{array}{c}\text { Estructura compuesta por } 2 \text { recintos circulares similares ( } 2 \mathrm{~m} \text { diámetro aprox.), hilada simple, } 40 \mathrm{~cm} \\
\text { de altura promedio. En superficie, fragmentos cerámicos Río Diablo y/o Ciénaga incisa. Asociada a } \\
\text { senderos. }\end{array}$ \\
\hline $\mathrm{PCHP}_{23}$ & $26^{\circ} 32^{\prime} 21.37^{\prime \prime} \mathrm{S}-67^{\circ} 14^{\prime} 43.16^{\prime \prime} \mathrm{O}-3533$ & Acumulación de rocas pequeñas, $1 \mathrm{~m} \times 1 \mathrm{~m}$, asociada a senderos entrelazados. \\
\hline $\mathrm{PCHP}_{24}$ & $26^{\circ} 32^{\prime} 41.29^{\prime \prime} \mathrm{S}-67^{\circ} 14^{\prime} 43.02^{\prime \prime} \mathrm{O}-3535$ & Estructura de muro simple semicircular, $1,5 \mathrm{~m} \times 1,5 \mathrm{~m}$, asociada a senderos. \\
\hline $\mathrm{PCHP}_{25}$ & $26^{\circ} 32^{\prime} 45.81^{\prime \prime} \mathrm{S}-67^{\circ} 14^{\prime} 44.24^{\prime \prime} \mathrm{O}-3535$ & Acumulación de rocas pequeñas, $1 \mathrm{~m} \times 1 \mathrm{~m}$, asociada a senderos entrelazados. \\
\hline $\mathrm{PCHP}_{2} 6$ & $26^{\circ} 32^{\prime} 55.86^{\prime \prime} \mathrm{S}-67^{\circ} 14^{\prime} 40.50^{\prime \prime} \mathrm{O}-3543$ & Estructura de muro simple semicircular, 1,5 $\mathrm{m} \mathrm{x} \mathrm{1,5m,} \mathrm{asociada} \mathrm{a} \mathrm{senderos.} \mathrm{Material} \mathrm{lítico} \mathrm{en} \mathrm{superficie.}$ \\
\hline $\mathrm{PCHP}_{27}$ & $26^{\circ} 33^{\prime} 44.91^{\prime \prime} \mathrm{S}-67^{\circ} 14^{\prime} 21.67^{\prime \prime} \mathrm{O}-35^{8} 1$ & Mojón asociado a senderos entrelazados/paralelos. \\
\hline $\mathrm{PCHP}_{2} 8$ & $26^{\circ} 33^{\prime} 48.64^{\prime \prime} \mathrm{S}-67^{\circ} 14^{\prime} 25.77^{\prime \prime} \mathrm{O}-3574$ & Acumulación de rocas pequeñas y clastos de cuarzo blanco, $1 \mathrm{~m}$ x $1 \mathrm{~m}$, asociada a senderos entrelazados. \\
\hline $\mathrm{PCHP}_{29}$ & $26^{\circ} 33^{\prime} 49.87^{\prime \prime} \mathrm{S}-67^{\circ} 14^{\prime} 27.78^{\prime \prime} \mathrm{O}-3570$ & Estructura de muro simple recto, 1,2 m de largo, asociado a senderos. \\
\hline $\mathrm{PCHP}_{3} \mathrm{O}$ & $26^{\circ} 33^{\prime} 48.25^{\prime \prime} \mathrm{S}-67^{\circ} 14^{\prime} 28.36^{\prime \prime} \mathrm{O}-3569$ & Mojón, $60 \mathrm{~cm}$, asociado a senderos entrelazados/paralelos. \\
\hline $\mathrm{PCHP}_{31}$ & $26^{\circ} 33^{\prime} 49.46^{\prime \prime} \mathrm{S}-67^{\circ} 14^{\prime} 30.22^{\prime \prime} \mathrm{O}-3566$ & 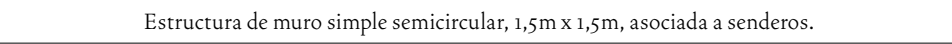 \\
\hline $\mathrm{PCHP}_{32}$ & $26^{\circ} 33^{\prime} 49.77^{\prime \prime} \mathrm{S}-67^{\circ} 14^{\prime} 31.80^{\prime \prime} \mathrm{O}-3564$ & $\begin{array}{c}\text { Conjunto de } 7 \text { estructuras de muro simple semicircular, sobre borde de loma baja. Fragmentos de vidrio } \\
\text { en superficie. }\end{array}$ \\
\hline $\mathrm{PCHP}_{33}$ & $26^{\circ} 33^{\prime} 56.00^{\prime \prime} \mathrm{S}-67^{\circ} 14^{\prime} 19.81^{\prime \prime} \mathrm{O}-35^{82}$ & Acumulación de rocas pequeñas, $1,5 \mathrm{~m} \times 1,5 \mathrm{~m}$, próxima a senderos entrelazados. \\
\hline $\mathrm{PCHP}_{34}$ & $26^{\circ} 34^{\prime} 13.78^{\prime \prime} \mathrm{S}-67^{\circ} 14^{\prime} 16.04^{\prime \prime} \mathrm{O}-35^{8} 7$ & Mojón, $60 \mathrm{~cm}$, asociado a senderos entrelazados/paralelos. \\
\hline $\mathrm{PCHP}_{35}$ & $26^{\circ} 34^{\prime} 17.15^{\prime \prime} \mathrm{S}-67^{\circ} 14^{\prime} 23.25^{\prime \prime} \mathrm{O}-3575$ & 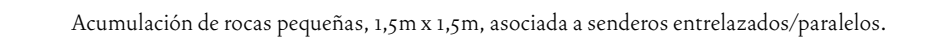 \\
\hline $\mathrm{PCHP}_{3} 6$ & $26^{\circ} 34^{\prime} 28.95^{\prime \prime} \mathrm{S}-67^{\circ} 14^{\prime} 25.51^{\prime \prime} \mathrm{O}-3569$ & Mojón, asociada a senderos entrelazados/paralelos. \\
\hline $\mathrm{PCHP}_{37}$ & $26^{\circ} 34^{\prime} 32.17^{\prime \prime} \mathrm{S}-67^{\circ} 14^{\prime} 24.59^{\prime \prime} \mathrm{O}-3570$ & Estructura de reparo rectangular abierta, hilada simple, $1,5 \mathrm{~m} \mathrm{x} \mathrm{1m}$, asociada a senderos. \\
\hline $\mathrm{PCHP}_{3} 8$ & $26^{\circ} 34^{\prime} 51.59^{\prime \prime} \mathrm{S}-67^{\circ} 14^{\prime} 20.85^{\prime \prime} \mathrm{O}-3576$ & 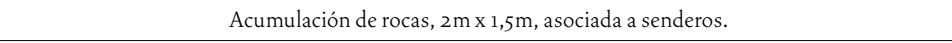 \\
\hline $\mathrm{PCHP}_{39}$ & $26^{\circ} 34^{\prime} 51.65^{\prime \prime} \mathrm{S}-67^{\circ} 14^{\prime} 21.70^{\prime \prime} \mathrm{O}-3574$ & Estructura de muro simple semicircular, $1,5 \mathrm{~m} \times 2 \mathrm{~m}$, asociada a senderos. \\
\hline $\mathrm{PCHP}_{4} \mathrm{O}$ & $26^{\circ} 34^{\prime} 55.15^{\prime \prime} \mathrm{S}-67^{\circ} 14^{\prime} 22.16^{\prime \prime} \mathrm{O}-3574$ & $\begin{array}{l}\text { Conjunto de } 11 \text { estructuras monticulares asociadas a depresiones artificiales de } 40 \mathrm{~cm} \times 40 \mathrm{~cm} \text {, sobre la } \\
\text { traza de los senderos. }\end{array}$ \\
\hline $\mathrm{PCHP}_{41}$ & $26^{\circ} 35^{\prime} 05.82^{\prime \prime} \mathrm{S}-67^{\circ} 14^{\prime} 23.64^{\prime \prime} \mathrm{O}-3572$ & Estructura de muro simple semicircular, $2 \mathrm{~m}$ x $2 \mathrm{~m}$, asociada a senderos. \\
\hline $\mathrm{PCHP}_{4} 2$ & $26^{\circ} 35^{\prime} 14.14^{\prime \prime} \mathrm{S}-67^{\circ} 14^{\prime} 25.95^{\prime \prime} \mathrm{O}-3570$ & 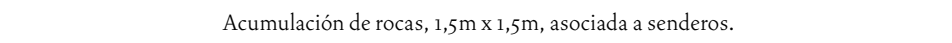 \\
\hline $\mathrm{PCHP}_{43}$ & $26^{\circ} 35^{\prime} 17.53^{\prime \prime} \mathrm{S}-67^{\circ} 14^{\prime} 20.69^{\prime \prime O}-3577$ & 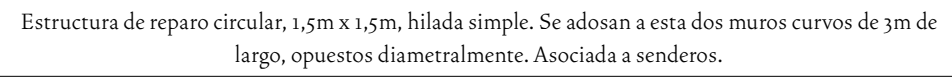 \\
\hline $\mathrm{PCHP}_{4} 4$ & $26^{\circ} 35^{\prime} 22.97^{\prime \prime} \mathrm{S}-67^{\circ} 14^{\prime} 21.44^{\prime \prime} \mathrm{O}-35^{8} 1$ & 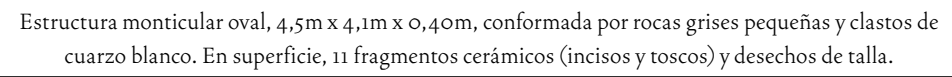 \\
\hline $\mathrm{PCHP}_{45}$ & $26^{\circ} 35^{\prime} 37.29^{\prime \prime} \mathrm{S}-67^{\circ} 14^{\prime} 18.17^{\prime \prime} \mathrm{O}-3603$ & Acumulación de clastos de cuarzo blanco, $40 \mathrm{~cm}$ x $40 \mathrm{~cm}$, asociada a senderos. \\
\hline $\mathrm{PCHP}_{4} 6$ & $26^{\circ} 35^{\prime} 44.76^{\prime \prime} \mathrm{S}-67^{\circ} 14^{\prime} 17.50^{\prime \prime} \mathrm{O}-3612$ & $\begin{array}{l}\text { Estructura de muro simple recto, } 50 \mathrm{~cm} \text { de altura y } 2,5 \mathrm{~m} \text { de largo, próximo a conjunto de fragmentos de } \\
\text { cerámica Belén N/R. Asociada a senderos. }\end{array}$ \\
\hline $\mathrm{PCHP}_{47}$ & $26^{\circ} 35^{\prime} 39.06^{\prime \prime} \mathrm{S}-67^{\circ} 14^{\prime} 23.42^{\prime \prime} \mathrm{O}-3598$ & 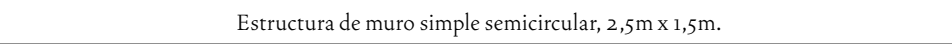 \\
\hline $\mathrm{PCHP}_{4} 8$ & $26^{\circ} 35^{\prime} 53.65^{\prime \prime} \mathrm{S}-67^{\circ} 14^{\prime} \circ 9.21^{\prime \prime} \mathrm{O}-3630$ & Estructura de muro simple recto de bloques medianos de basalto, $2 \mathrm{~m}$ de largo. \\
\hline
\end{tabular}

Tabla 2. Sitios asociados a senderos del Ramal 2 de Peñas Chicas del Peñón. 


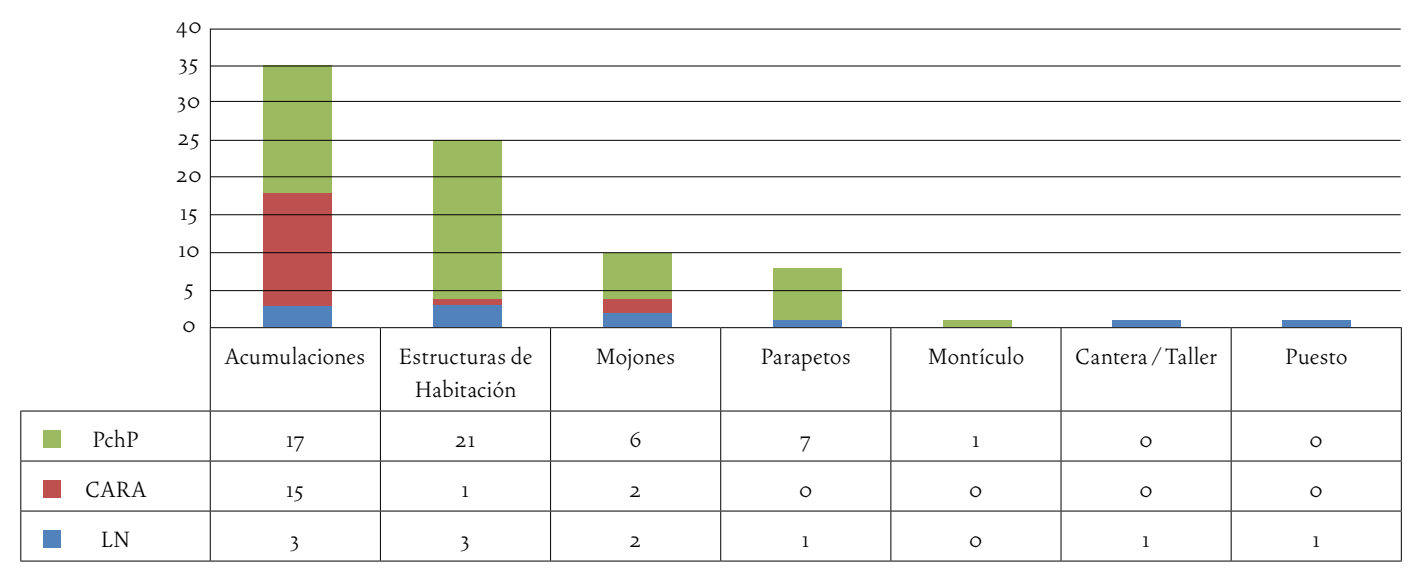

Gráfico 1. Variabilidad de sitios registrados en los 3 sectores identificados.

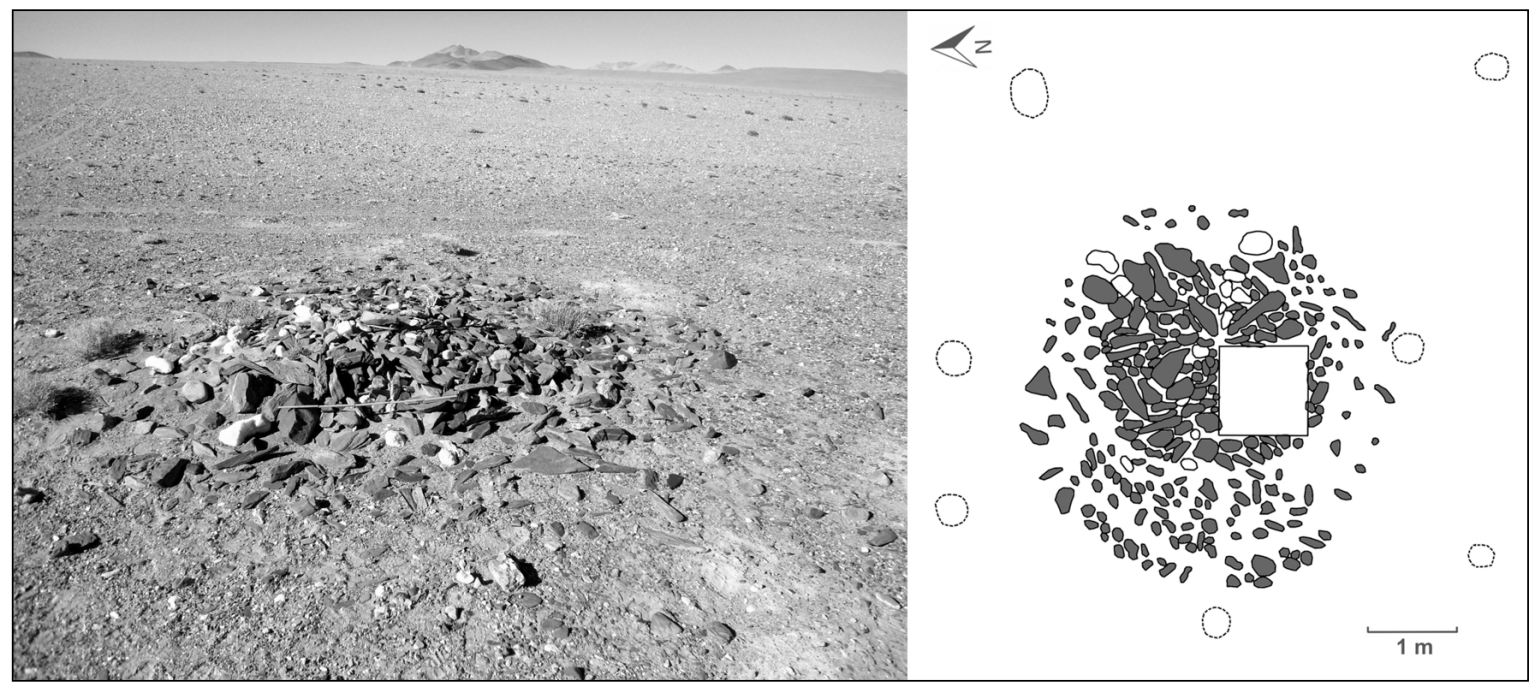

Figura 5. Sitio PChP 44. Montículo asociado a senderos.

En el montículo, sitio PChP 44 (S 26 35'22.97", O $\left.67^{\circ} 14^{\prime} 21.44^{\prime \prime}, 3581 \mathrm{msnm}\right)$ se pudo recuperar en superficie 11 fragmentos cerámicos pequeños (Figura 6). Solo uno de estos fragmentos presentaba decoración por modificación de su superficie externa mediante la aplicación de las técnicas de incisión de puntos, haciéndolo comparable a diversos materiales cerámicos, recuperados en la localidad de Laguna Blanca, asignados a estilos formativos como Condorhuasi-Río Diablo, Saujil y Ciénaga (Valeria Espiro, com. pers. 2015).

Por su parte, el sondeo realizado sobre el montículo ( $1 \mathrm{x} 1 \mathrm{~m})$, permitió definir diversos aspectos de su conformación y recuperar evidencia significativa para una asignación cronológica relativa. En primer lugar, el perfil obtenido muestra una total ausencia de estratigrafía y una composición exclusiva de clastos medianos a grandes en la que no pudimos identificar ningún criterio de selección u ordenamiento de los mismos. Dentro de esta matriz rocosa, el sedimento solo ocupaba los espacios intersticiales entre los clastos. En definitiva, podemos plantear que el proceso de conformación de este montículo involucró sucesivas acciones de colocación de rocas de un modo aleatorio y reiterado durante un espacio determinado de tiempo, denotando una práctica social concreta cuya recurrencia le otorga un carácter netamente ceremonial, asociada a la circulación de las personas que con cierta frecuencia transitaban esta vía. 


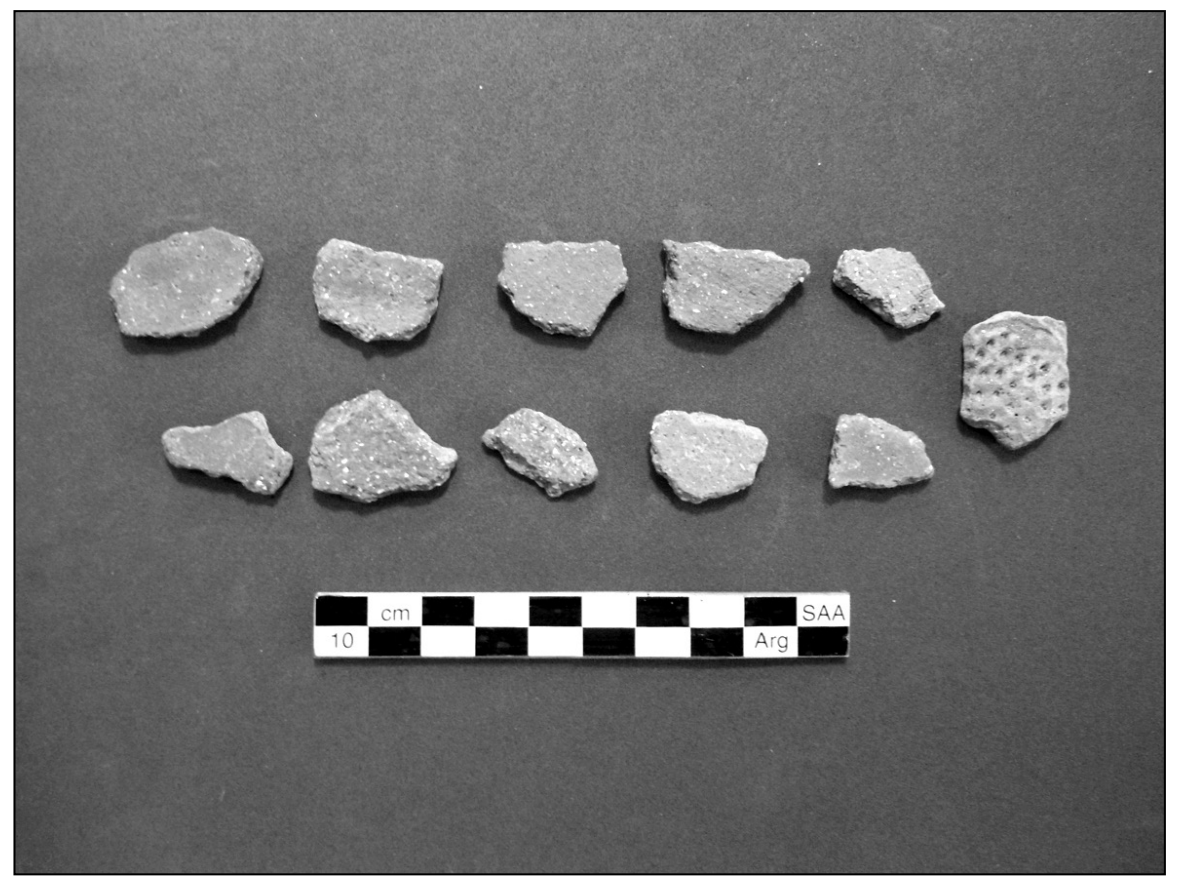

Figura 6. Fragmentos cerámicos asociados al montículo.

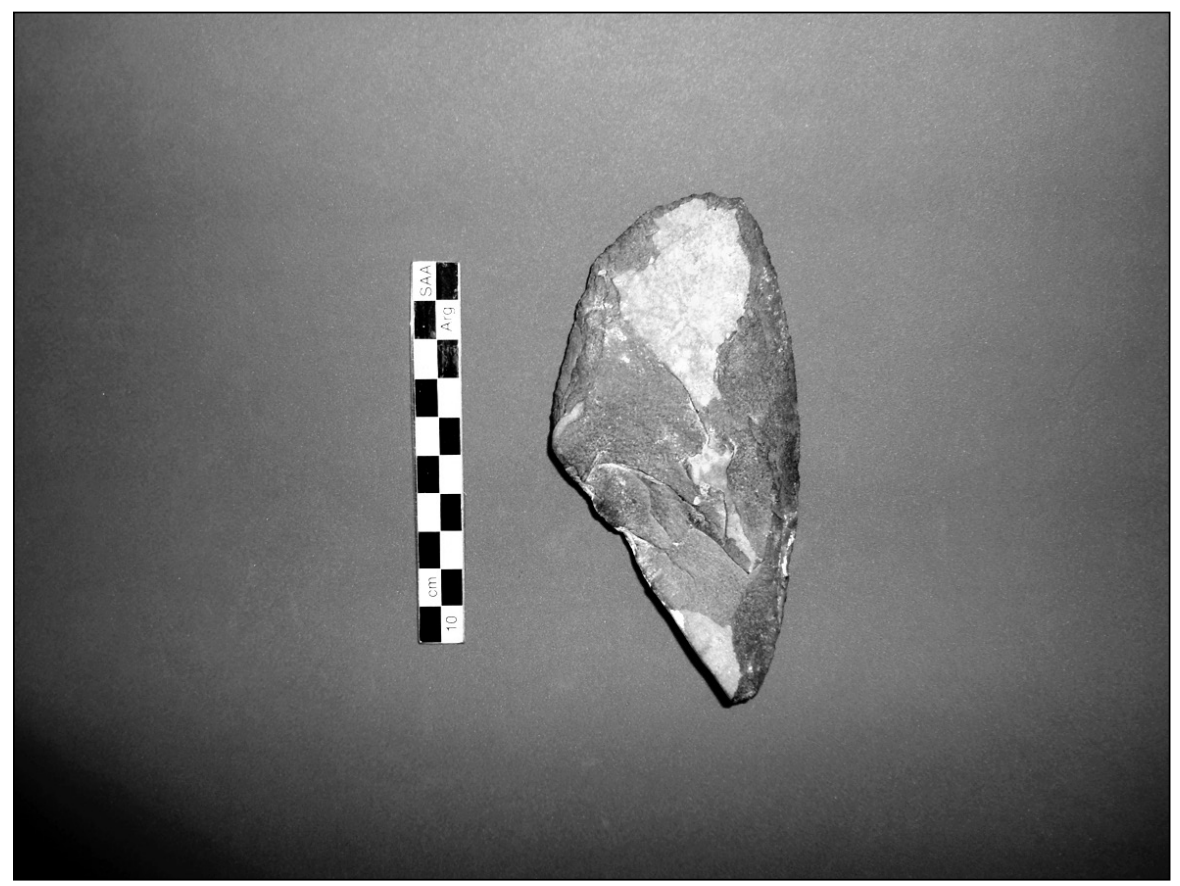

Figura 7. Cuchillo/raedera recuperado durante el sondeo del montículo. 
Mediante el sondeo recuperamos también un artefacto lítico de vulcanita correspondiente a un cuchillo/raedera (Figura 7), comparable tecno-morfológicamente a los cuchillos/raederas de módulo grandísimo, registrados en sitios de ANS y vinculados a una cronología entre 1700 y 1200 AP (Escola et al. 2013). Esta adscripción temporal, si bien relativa, encuentra cierta coherencia con el registro cerámico mencionado, permitiéndonos postular una data formativa para el montículo.

Cabe destacar las características del emplazamiento del montículo ya que refuerza su carácter singular. Éste se encuentra en un punto donde el terreno presenta una marcada inflexión de la pendiente general, coincidiendo con el inicio del tramo de la ruta que permite el acceso al Abra de Pasto Ventura. Si analizamos su ubicación en función de desplazamientos norte-sur (p.e. entre El Peñón y Laguna Blanca), es el punto del espacio donde finaliza la posibilidad de un tránsito menos exigente y comienza un ascenso más riguroso.

Estructuras de habitación y/o reparo: posibilidad de pernocte. El registro realizado en este tramo de $12 \mathrm{~km}$ se completa con 19 estructuras de habitación y/o reparo que habilitan posibilidad de pernocte: 16 parapetos, un recinto rectangular abierto y dos estructuras compuestas. Si bien en la mayoría de los casos el registro de materiales en superficie fue negativo, algunas estructuras presentaban evidencia asociada a ocupaciones transitorias de diversa cronología: fragmentos cerámicos Ciénaga y Belén, desechos de talla de vulcanitas, botellas y restos de botellas de vidrio y latas de conservas. Esto pone de manifiesto la profundidad temporal y continuidad de uso de esta vía de circulación que permitió el tránsito de personas, animales y el tráfico de bienes y recursos entre nodos puneños y vallistos, desde momentos formativos hasta históricos recientes.

En términos constructivos, todas las estructuras presentan iguales características: muros simples de pirka seca y baja altura, escasa selección de las rocas utilizadas y sujeta a la disponibilidad inmediata. Es decir, estructuras expeditivas de muy baja inversión de energía, característica común en la mayoría de los campamentos caravaneros, tanto en contextos etnográficos como arqueológicos (Nielsen 1997, 1997-1998).
Las excavaciones realizadas en el sitio PChP 43 (S $26^{\circ} 35^{\prime} 17.53^{\prime \prime}$, O $67^{\circ} 14^{\prime} 20.69^{\prime \prime}, 3577 \mathrm{msnm}$ ), una estructura compuesta por un recinto circular al que se le adosan dos muros semicirculares a ambos lados y que se asocia directamente a los senderos (Figura 8), no permitieron la recuperación de materiales en estratigrafía. Sin embargo, los análisis de microfósiles, ${ }^{4}$ realizados en las muestras de sedimentos, dieron cuenta de la presencia de esferulitas (Korstanje 2004) seguramente provenientes de las fecas de camélidos, fitolitos de maíz y agregados de cristales de oxalato de calcio característicos de algunos tubérculos, elementos que nos llevan a interpretar esta estructura como un campamento o sitio de pernocte que ocuparon personas que viajaban con animales y donde se prepararon y consumieron alimentos. En el sondeo realizado contra el muro E de la estructura, se pudo definir un evento de fogón que arrojó una fecha de $1760 \pm 60$ años AP (LP-3303, cal. 10: 247 AD - 380 AD).

A su vez, sondeos realizados en PChP 22 ( $\mathrm{S}_{26} 6^{\circ} 32^{\prime} 15.20^{\prime \prime}$, O $67^{\circ} 14^{\prime} 47.28^{\prime \prime}, 3528 \mathrm{msnm}$ ), una estructura compuesta por dos recintos circulares de similares dimensiones (1 $\mathrm{m} \varnothing$ aprox.) con muros de pirka de hilada simple $(40 \mathrm{~cm}$ de altura promedio), permitieron la recuperación de cinco fragmentos cerámicos posiblemente pertenecientes al mismo objeto cerámico, el cual parece ser una vasija cerrada de perfil compuesto identificada como jarra (Figura 9). Se puede observar que al menos poseía un asa de posición vertical en forma de cinta. La cocción de la vasija es reductora y la coloración a simple vista es grisácea. La técnica de tratamiento de superficie comprende alisado y pulido. La vasija presenta decoración por modificación de su superficie externa mediante la aplicación de las técnicas de incisión y excisión. Los motivos de la decoración observada son lineales y geométricos; entre los primeros se observan líneas oblicuas paralelas y entre los segundos líneas formando triángulos que a su vez están rellenos de puntos. El conjunto presenta muchas similitudes tecnoestilísticas con una jarra Condorhuasi-Río Diablo recuperada en Laguna Blanca en el yacimiento Aldea Piedra Negra, en un contexto funerario del sitio PIN-68 (Valeria Espiro, com. pers. 2015).

4 Los análisis fueron realizados por las técnicas Julieta Zapatiel (UNT, CONICET) y Mónica Burgos (ISES, CONICET) del Laboratorio de Arqueobotánica del Instituto de Arqueología y Museo de la Universidad Nacional de Tucumán, dirigido por Alejandra Korstanje (UNT, CONICET). 


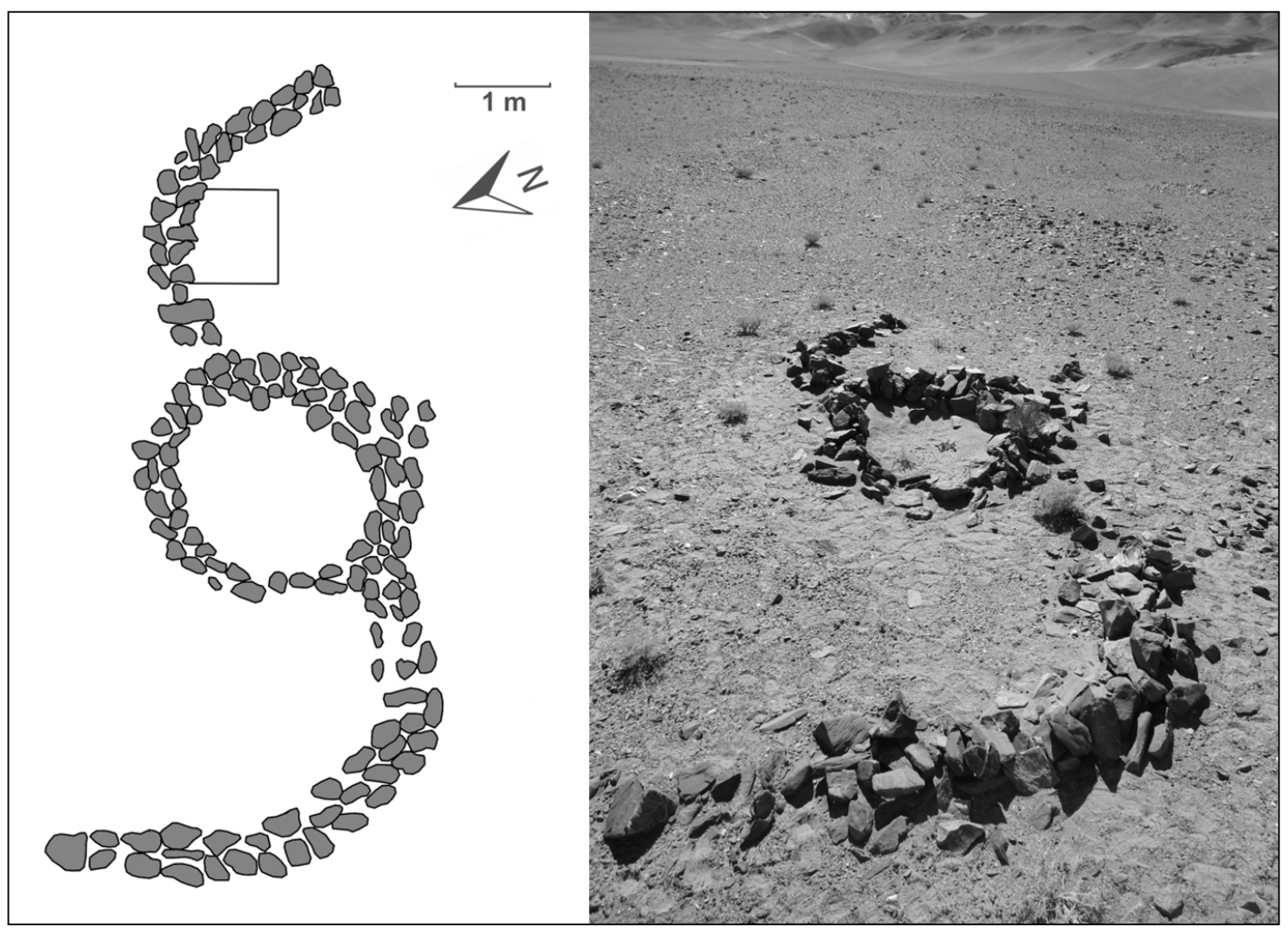

Figura 8. Sitio PChP 43. Estructura de habitación asociada a senderos. Se excavó el recinto central completo y se efectuó un sondeo contra el muro E.

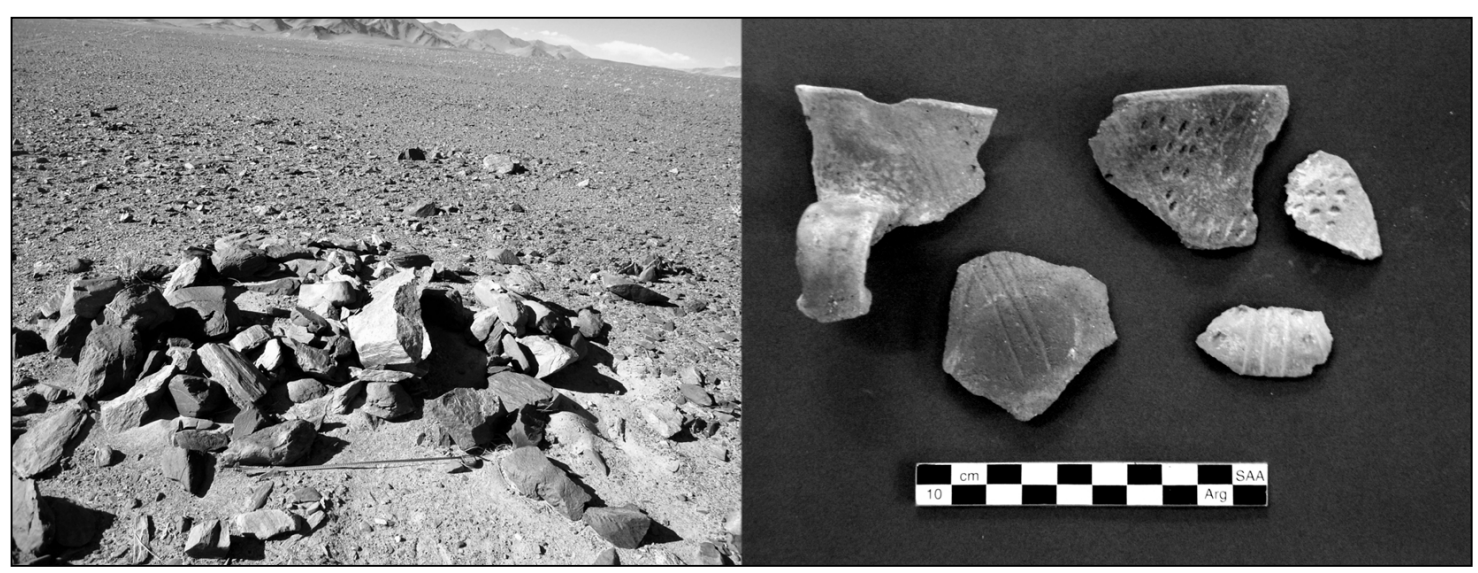

Figura 9. Sitio PChP 22. Estructura de habitación asociada a senderos y fragmentos de la jarra cerámica recuperada en el sondeo. 


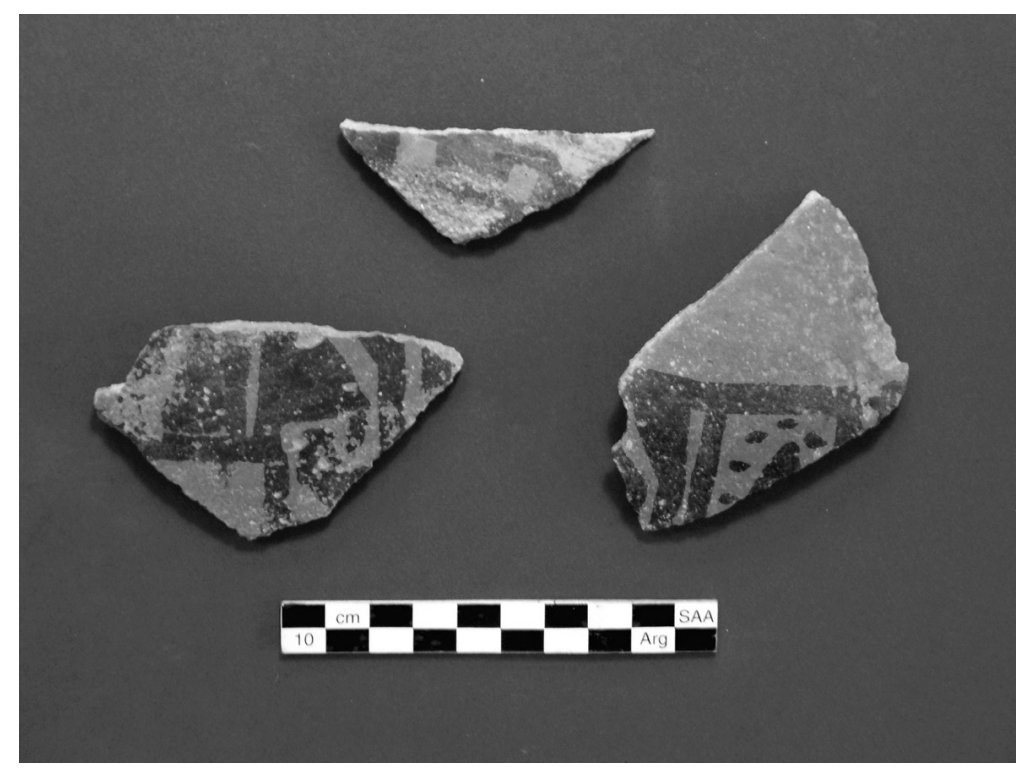

Figura 10. Fragmentos cerámicos Belén N/R recuperados en el sitio PChP 46, parapeto asociado a senderos.

Otro sitio asociado a los senderos, PChP 46 (S $26^{\circ} 35^{\prime} 44.76^{\prime \prime}$, O $\left.67^{\circ} 14^{\prime} 17.50^{\prime \prime}, 3612 \mathrm{msnm}\right)$, también aportó información diagnóstica. Se trata de un muro de pirka de hilada simple de $50 \mathrm{~cm}$ de altura y $2,5 \mathrm{~m}$ de largo, que habría funcionado como parapeto o estructura de resguardo temporaria. Allí pudimos recuperar en superficie un conjunto de fragmentos de cerámica Belén N/R (Figura 10).

En síntesis, podemos decir que el registro arqueológico de la planicie de Peñas Chicas de El Peñón responde a las expectativas que surgen al momento de plantear una investigación sobre interacciones sociales y tráfico interregional en el marco de una arqueología internodal; algo que Nielsen (2003) definió con mayor precisión al destacar que es precisamente la evidencia "que ofrece el registro arqueológico directamente generado a lo largo de las rutas por el traslado de personas, bienes y tal vez animales de carga, lo que podríamos considerar como la expresión conductual básica de aquellos procesos [de interacción]" (op. cit.: 262).

\section{Carachipampa}

A escasos $10 \mathrm{~km}$ al noroeste de la planicie de Peñas Chicas del Peñón se accede a la vecina y más extensa planicie de Carachipampa (en adelante CP), la cual media entre El Pe- ñón (EP) y la localidad de Antofagasta de la Sierra (ANS). En este punto se presentan dos opciones de tránsito principales: seguir hacia el oeste hasta el volcán y laguna Carachipampa, donde se alcanza la senda (actualmente camino de 4x4) que permite la conexión entre ANS con las localidades de Palo Blanco, Saujil y Fiambalá en el valle de Abaucán, o bien, continuar hacia el norte por el borde este de CP hasta ANS. Esta última opción constituyó la segunda etapa de nuestro trabajo (Figura 11).

En el análisis previo de las imágenes satelitales habíamos detectado una posible vía de circulación que se extendía desde el sector sureste de CP hasta la colada del complejo volcánico Los Negros, en el extremo noreste de la planicie, completando una longitud de $24 \mathrm{~km}$. Una vez ubicados y definidos los senderos en el terreno, se pudo constatar que se trataba de una vía de circulación que, en este sector, se componía de 17 sendas en un ancho de 10 $\mathrm{m}$ y dispuestas mayormente en forma paralela, aunque en algunos tramos pudimos registrar sendas superpuestas que definían un patrón entrelazado, contabilizando un centenar de senderos que llegan a conformar un ancho de vía de unos $60 \mathrm{~m}$ (Figura 12). Este hecho nos permite plantear una posible superposición de una vía tropera histórica sobre una vía caravanera prehispánica. Es decir, en CP se daría la misma situación respecto de las vías de circulación registradas en PChP. 


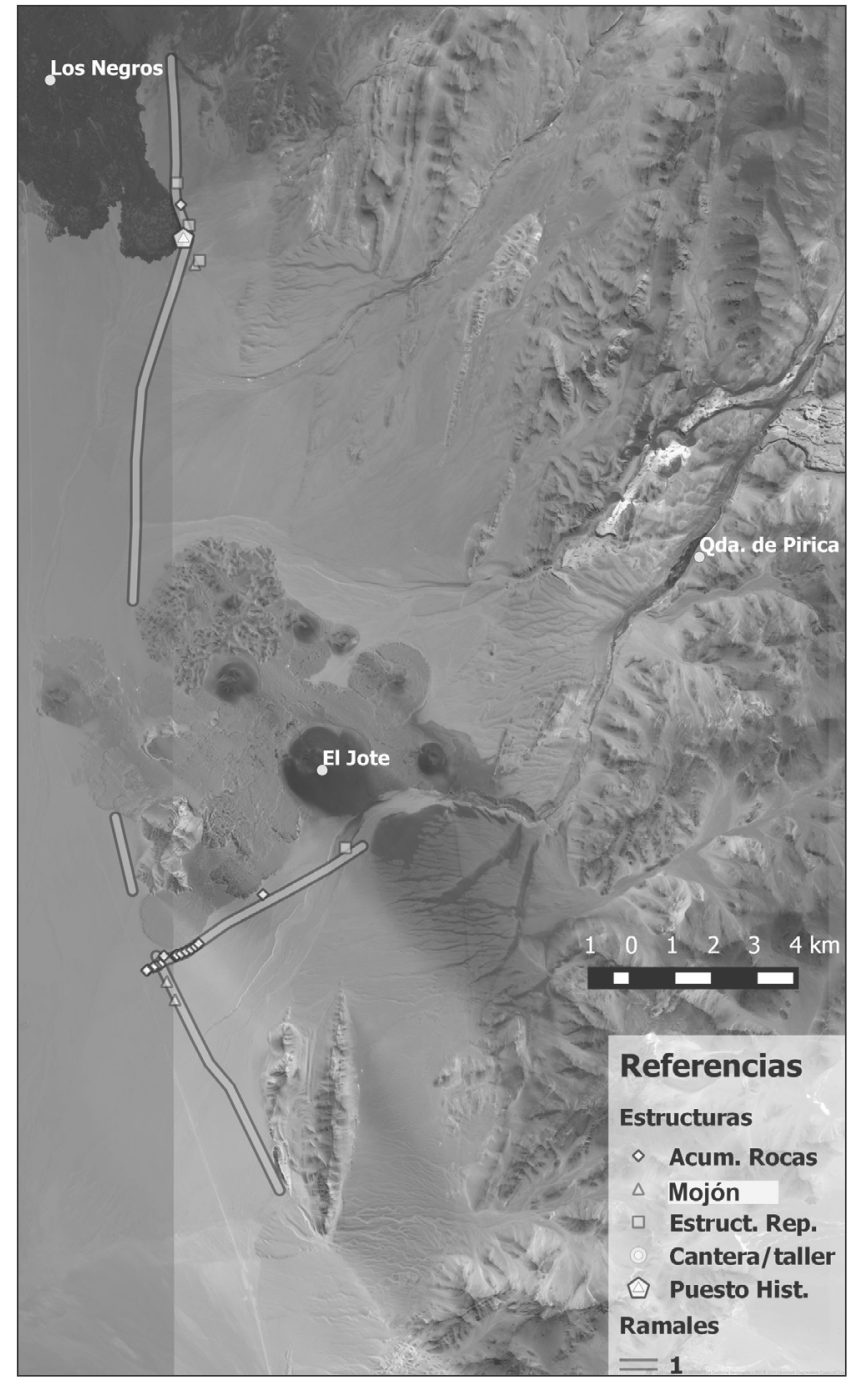

Figura 11. Distribución de sitios asociados a la vía de circulación en Carachipampa.

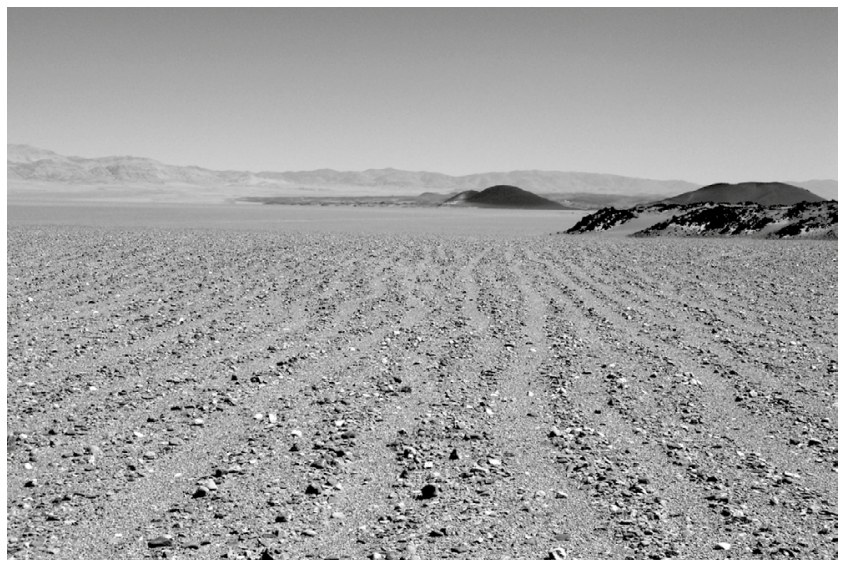

Figura 12. Senderos en la planicie de Carachipampa. 
El primer tramo es de $9 \mathrm{~km}$, sentido sur-norte, y va desde el paso que comunica EP con CP (S $26^{\circ} 26^{\prime} 39,29^{\prime \prime} ; \mathrm{O}$ $\left.67^{\circ} 19^{\prime} 20,71^{\prime \prime} ; 3210 \mathrm{msnm}\right)$ hasta la entrada de la quebrada de Pirica, sector conocido como El Jote, que es donde se emplaza el volcán Carducci (S 26 22'03,62"; O $67^{\circ} 22^{\prime} 13,34^{\prime \prime} ; 3106 \mathrm{msnm}$ ) y donde registramos un cruce con otra vía de circulación que vincula - con sentido oeste-este- la laguna de Carachipampa con las vegas del sector inferior de la quebrada de Pirica. El registro de superficie resultó escaso y acotado a materiales históricos (fragmentos de vidrio y latas de conserva). En cuanto a estructuras, pudimos registrar dos mojones $(40$ a $45 \mathrm{~cm}$ de altura), posiblemente históricos, asociados directamente a la vía y próximos al punto donde algunos senderos se separan y giran hacia el este para internarse en la quebrada de Pirica.

Por su parte, asociados a los senderos que ingresan en la quebrada mencionada, pudimos registrar un conjunto de 13 acumulaciones de rocas que comparten idénticas características formales (Tabla 3). En primer lugar, éstas se disponen alineadas en sentido este-oeste a lo largo de $1,5 \mathrm{~km}$, a distancias variables una de otra. Esta alineación es perpendicular a la vía principal y, en parte, paralela a los senderos que entran hacia Pirica. En todos los casos se trata de acumulaciones circulares a subcirculares de 1 $\mathrm{m}$ a 1,5 $\mathrm{m}$ de diámetro y escasa altura (menor de $15 \mathrm{~cm}$ ), compuestas por clastos medianos a pequeños con predominio de cuarzo blanco (Figura 13). En ningún caso se registraron materiales asociados, lo cual imposibilita - por el momento- una asignación cronológica relativa. De todos modos, teniendo en cuenta diversos trabajos sobre esta temática en el área andina, nos permite generar hipótesis sobre su posible relación con prácticas ceremoniales de los viajeros en tránsito (Pimentel 2009).

En este sector de El Jote-Pirica, los senderos que siguen hacia ANS desaparecen (erosión eólica e impacto antrópico por obras viales) y vuelven a registrarse $6 \mathrm{~km}$ al norte (S 26 ${ }^{\circ} 17^{\prime} 43,43^{\prime \prime} ; \mathrm{O} 67^{\circ} 22^{\prime} 37,02^{\prime \prime} ; 3169 \mathrm{msnm}$ ), posibilitando un recorrido de otros $9 \mathrm{~km}$ hasta alcanzar el extremo sureste de la colada basáltica del complejo volcánico Los Negros (S 26 ${ }^{\circ} 12^{\prime} 42,60^{\prime \prime} ;$ O 67 $21^{\circ} 54,70^{\prime \prime} ; 3241$ $\mathrm{msnm})$. Este último tramo transita el sector noreste de $\mathrm{CP}$; aquí la conservación de los senderos es mala y resulta muy difícil su seguimiento. A su vez, no se registraron materiales y rasgos asociados durante su recorrido.
En los análisis previos de las imágenes satelitales habíamos detectado que en este sector sureste de la colada de Los Negros, confluían distintas vías que provenían de la parte central y sur de CP, lo cual aumentaba las probabilidades de hallazgos por tratarse de un espacio de uso y/o tránsito redundante. Efectivamente, en la irregularidad natural del borde de la colada, donde sus espacios ofrecen buen resguardo de los vientos, pudimos registrar dos puestos pastoriles y numerosos campamentos que, en todos los casos, presentaban materiales históricos, principalmente, botellas de vidrio y latas de conservas. En este punto los senderos continúan su rumbo norte, bordeando el límite este de la colada. Aquí pudimos registrar cuatro estructuras de reparo asociadas a la vía de circulación, de las cuales dos de ellas presentaban desechos de talla y artefactos líticos realizados sobre vulcanitas (Figura 14), y un mojón con el mismo tipo de material lítico asociado (Tabla 4).

La irregularidad del terreno (borde de la colada) truncó la posibilidad de continuar el seguimiento de este tramo de la vía de circulación, ya que los senderos perdían visibilidad entre los numerosos clastos basálticos. Por lo tanto, tuvimos que rodear todo el complejo volcánico de Los Negros por su lado oeste hasta alcanzar el extremo noreste de la colada, donde constatamos la continuidad de los senderos en ese sector (S 26 $6^{\circ} 8^{\prime} 17,7^{\prime \prime}$; O $\left.67^{\circ} 22^{\prime} 15,94^{\prime \prime} ; 3390 \mathrm{msnm}\right)$. Desde este punto, se logra el ingreso directo a la parte baja y final de la cuenca del río Punilla, donde se encuentran la laguna Antofagasta, los sitios de mayor envergadura de los Períodos PDR e Inka (La Alumbrera, el Coyparcito y los campos agrícolas de Bajo el Coypar) y el actual pueblo de ANS.

De un modo sintético, podemos decir que los trabajos desarrollados nos permitieron el registro, documentación y georreferenciación de $60 \mathrm{~km}$ de una vía de circulación que conecta el Abra de Pasto Ventura con Antofagasta de la Sierra (conformada por vías caravaneras prehispánicas, vías troperas históricas y su evidencia material asociada), la cual posibilitó -mediante diversos modos de movilidad- la interacción social entre comunidades puneñas y vallistas a lo largo del tiempo, desde momentos formativos hasta históricos recientes. Cabe destacar que, hasta el momento, no se disponía para el área de estudio de un trabajo de estas características, es decir, de un registro positivo de las vías de circulación y los restos materiales directamente asociados a éstas. 


\section{Alvaro Martel, Diego Zamora y Matías Lépori}

\begin{tabular}{|c|c|c|}
\hline Sitio & Coordenadas - msnm & Tipo de sitio \\
\hline $\mathrm{CARA}_{4}$ & $26^{\circ} 22^{\prime} 31.98^{\prime \prime} \mathrm{S}-67^{\circ} 21^{\prime} 58.62^{\prime \prime O}-3103$ & Mojón (40 cm) asociado a senderos. \\
\hline CARA 5 & $26^{\circ} 22^{\prime} 17.64^{\prime \prime} \mathrm{S}-67^{\circ} 22^{\prime} 05.77^{\prime \prime O}-3103$ & Mojón (40cm) asociada a senderos. \\
\hline CARAG & $26^{\circ} 22^{\prime} 04.29^{\prime \prime} \mathrm{S}-67^{\circ} 22^{\prime} 11.38^{\prime \prime} \mathrm{O}-3107$ & Acumulación de rocas grises y clastos de cuarzo blanco, $1,5 \mathrm{mx} 1 \mathrm{~m}$ aprox. \\
\hline CARA7 & $26^{\circ} 22^{\prime} 05.91^{\prime \prime} \mathrm{S}-67^{\circ} 22^{\prime} 15.24^{\prime \prime} \mathrm{O}-3106$ & Acumulación de rocas grises y clastos de cuarzo blanco, $1,5 \mathrm{mx} 1 \mathrm{~m}$ aprox. \\
\hline CARA8 & $26^{\circ} 22^{\prime} 06.48^{\prime \prime} \mathrm{S}-67^{\circ} 22^{\prime} 17.74^{\prime \prime} \mathrm{O}-3104$ & Acumulación de rocas grises y clastos de cuarzo blanco, $1,5 \mathrm{mx} 1 \mathrm{~m}$ aprox. \\
\hline CARA9 & $26^{\circ} 22^{\prime} 08.49^{\prime \prime} \mathrm{S}-67^{\circ} 22^{\prime} 22.39^{\prime \prime} \mathrm{O}-3102$ & Acumulación de rocas grises y clastos de cuarzo blanco, $1,5 \mathrm{mx} 1 \mathrm{~m}$ aprox. \\
\hline CARAIO & $26^{\circ} 22^{\prime} 09.06^{\prime \prime} \mathrm{S}-67^{\circ} 22^{\prime} 23.62^{\prime \prime} \mathrm{O}-3101$ & Acumulación de rocas grises y clastos de cuarzo blanco, $1,5 \mathrm{mx} 1 \mathrm{~m}$ aprox. \\
\hline CARAll & $26^{\circ} 21^{\prime} 57.59^{\prime \prime} \mathrm{S}-67^{\circ} 22^{\prime} 08.35^{\prime \prime} \mathrm{O}-3110$ & Acumulación de rocas grises y clastos de cuarzo blanco, $1,5 \mathrm{mx} 1 \mathrm{~m}$ aprox. \\
\hline CARAl2 & $26^{\circ} 21^{\prime} 57.70^{\prime \prime S}-67^{\circ} 21^{\prime} 58.37^{\prime \prime O}-3115$ & Acumulación de rocas grises y clastos de cuarzo blanco, $1,5 \mathrm{mx} 1 \mathrm{~m}$ aprox. \\
\hline CARA13 & $26^{\circ} 21^{\prime} 57.24^{\prime \prime} \mathrm{S}-67^{\circ} 21^{\prime} 57.89^{\prime \prime} \mathrm{O}-3115$ & Acumulación de rocas grises y clastos de cuarzo blanco, $1,5 \mathrm{mx} 1 \mathrm{~m}$ aprox. \\
\hline CARAl4 & $26^{\circ} 21^{\prime} 56.85^{\prime \prime} \mathrm{S}-67^{\circ} 21^{\prime} 56.88^{\prime \prime} \mathrm{O}-3116$ & Acumulación de rocas grises y clastos de cuarzo blanco, $1,5 \mathrm{mx} 1 \mathrm{~m}$ aprox. \\
\hline CARA15 & $26^{\circ} 21^{\prime} 55.83^{\prime \prime} \mathrm{S}-67^{\circ} 21^{\prime} 53.11^{\prime \prime} \mathrm{O}-3117$ & Acumulación de rocas grises y clastos de cuarzo blanco, $1,5 \mathrm{mx} 1 \mathrm{~m}$ aprox. \\
\hline CARAi6 & $26^{\circ} 21^{\prime} 53.95^{\prime \prime} \mathrm{S}-67^{\circ} 21^{\prime} 48.73^{\prime \prime O}-3118$ & Acumulación de rocas grises y clastos de cuarzo blanco, $1,5 \mathrm{mx} 1 \mathrm{~m}$ aprox. \\
\hline CARAi7 & $26^{\circ} 21^{\prime} 52.30^{\prime \prime} \mathrm{S}-67^{\circ} 21^{\prime} 44.46^{\prime \prime} \mathrm{O}-3122$ & Acumulación de rocas grises y clastos de cuarzo blanco, $1,5 \mathrm{mx} 1 \mathrm{~m}$ aprox. \\
\hline CARA18 & $26^{\circ} 21^{\prime} 49.98^{\prime \prime} \mathrm{S}-67^{\circ} 21^{\prime} 40.72^{\prime \prime} \mathrm{O}-3122$ & Acumulación de rocas grises y clastos de cuarzo blanco, $1,5 \mathrm{mx} 1 \mathrm{~m}$ aprox. \\
\hline CARAl9 & $26^{\circ} 21^{\prime} 47.92^{\prime \prime} \mathrm{S}-67^{\circ} 21^{\prime} 37.92^{\prime \prime} \mathrm{O}-3124$ & Acumulación de rocas grises y clastos de cuarzo blanco, $1,5 \mathrm{mx} 1 \mathrm{~m}$ aprox. \\
\hline CARA2O & $26^{\circ} 21^{\prime} 09.29^{\prime \prime} \mathrm{S}-67^{\circ} 20^{\prime} 41.40^{\prime \prime} \mathrm{O}-3168$ & Acumulación de rocas grises y clastos de cuarzo blanco, $1,5 \mathrm{mx} 1 \mathrm{~m}$ aprox. \\
\hline CARA21 & $26^{\circ} 20^{\prime} 32.46^{\prime \prime} \mathrm{S}-67^{\circ} 19^{\prime} 29.00^{\prime \prime} \mathrm{O}-3200$ & Estructura de reparo circular, $1,5 \mathrm{mxl}, 5 \mathrm{~m}$, bloques grandes a medianos. \\
\hline
\end{tabular}

Tabla 3. Sitios asociados a senderos de la vía de circulación en Carachipampa.

\begin{tabular}{|c|c|c|}
\hline Nombre de sitio & Coordenadas - msnm & Tipo de sitio \\
\hline $\mathrm{LN}_{1}$ & $26^{\circ} 12^{\prime} 53.17^{\prime \prime S}-67^{\circ} 21^{\prime} 41.22^{\prime \prime} \mathrm{O}-3227$ & Mojón (8ocm) asociado a senderos. Lascas de vulcanita en superficie. \\
\hline $\mathrm{LN}_{2}$ & $26^{\circ} 12^{\prime} 50.04^{\prime \prime} \mathrm{S}-67^{\circ} 21^{\prime} 37.04^{\prime \prime} \mathrm{O}-3231$ & Estructura de reparo circular, $2,2 \times 2 \mathrm{~m}$, bloques grandes, asociada a senderos. \\
\hline $\mathrm{LN}_{3}$ & $26^{\circ} 12^{\prime} 22.31^{\prime \prime S}-67^{\circ} 21^{\prime} 46.27^{\prime \prime O}-3241$ & Estructura de reparo circular, $2 \times 2 \mathrm{~m}$, bloques grandes, asociada a senderos. \\
\hline $\mathrm{LN}_{4}$ & $26^{\circ} 12^{\prime} 06.05^{\prime \prime} \mathrm{S}-67^{\circ} 21^{\prime} 53.51^{\prime \prime} \mathrm{O}-3242$ & Acumulación de rocas grises, 1 xım aprox., asociada a senderos. \\
\hline $\mathrm{LN}_{5}$ & $26^{\circ} 11^{\prime} 48.96^{\prime \prime} \mathrm{S}-67^{\circ} 21^{\prime} 56.85^{\prime \prime} \mathrm{O}-3252$ & Parapeto, $2 \mathrm{~m}$ de longitud, material lítico en superficie. Asociado a senderos. \\
\hline LN6 & $26^{\circ} 7^{\prime} 50.10^{\prime \prime} \mathrm{S}-67^{\circ} 22^{\prime} 41.14^{\prime \prime O}-3378$ & Mojón ( $50 \mathrm{~cm}$ ) asociada a senderos. \\
\hline $\mathrm{LN}_{7}$ & $26^{\circ} 7^{\prime} 46.53^{\prime \prime} \mathrm{S}-67^{\circ} 22^{\prime} 39.97^{\prime \prime O}-3378$ & Acumulación de rocas grises, 1 xım aprox., asociada a senderos. \\
\hline LN8 & $26^{\circ} 7^{\prime} 51.54^{\prime \prime} \mathrm{S}-67^{\circ} 22^{\prime} 35.41^{\prime \prime O}-3379$ & Estructura circular, $2 \times 2 \mathrm{~m}$, asociada a talleres líticos, próximos a senderos. \\
\hline LN9 & $26^{\circ} 8^{\prime} 17.50^{\prime \prime S}-67^{\circ} 22^{\prime} 16.32^{\prime \prime O}-3391$ & Cantera/taller asociada a senderos. \\
\hline LN1O & $26^{\circ} 7^{\prime} 42.35^{\prime \prime} \mathrm{S}-67^{\circ} 22^{\prime} 35.55^{\prime \prime O}-3383$ & Acumulación de rocas grises, 1 xım aprox., asociada a senderos. \\
\hline
\end{tabular}

Tabla 4. Sitios asociados a senderos en el sector de Los Negros. 


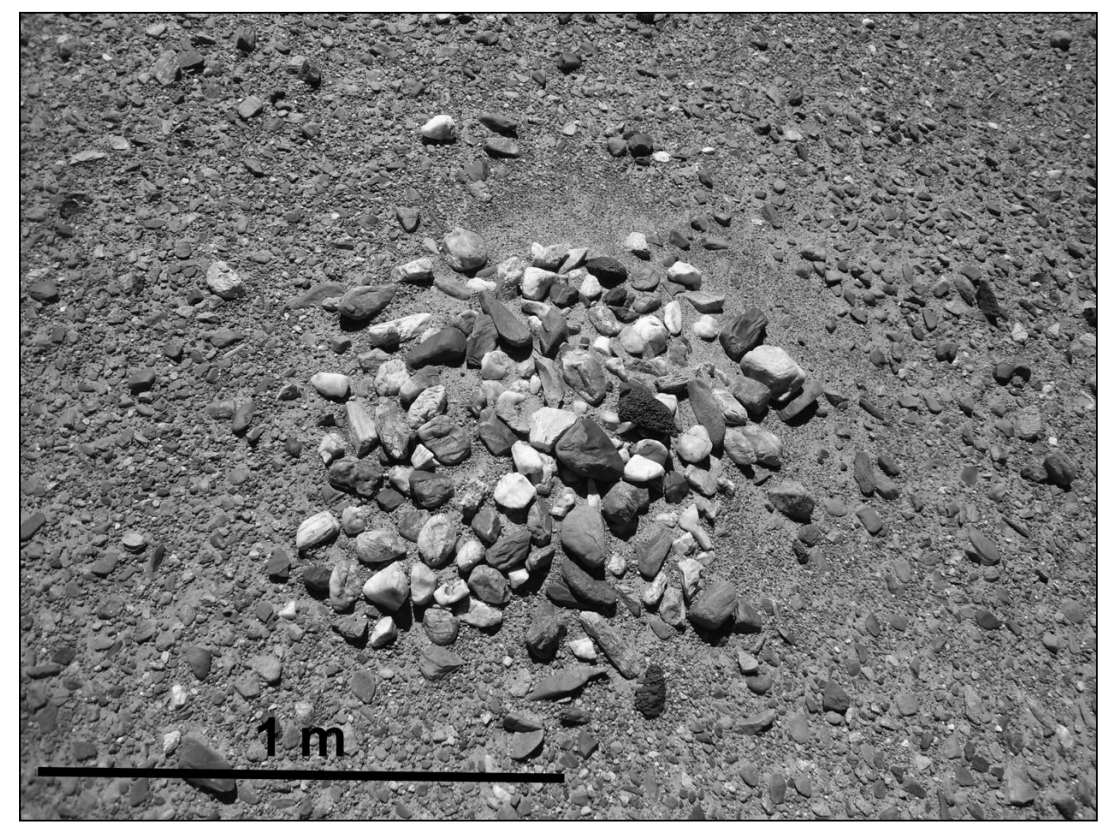

Figura 13. Una de las acumulaciones de rocas con clastos de cuarzo blanco, próximas a la entrada de la quebrada de Pirica.

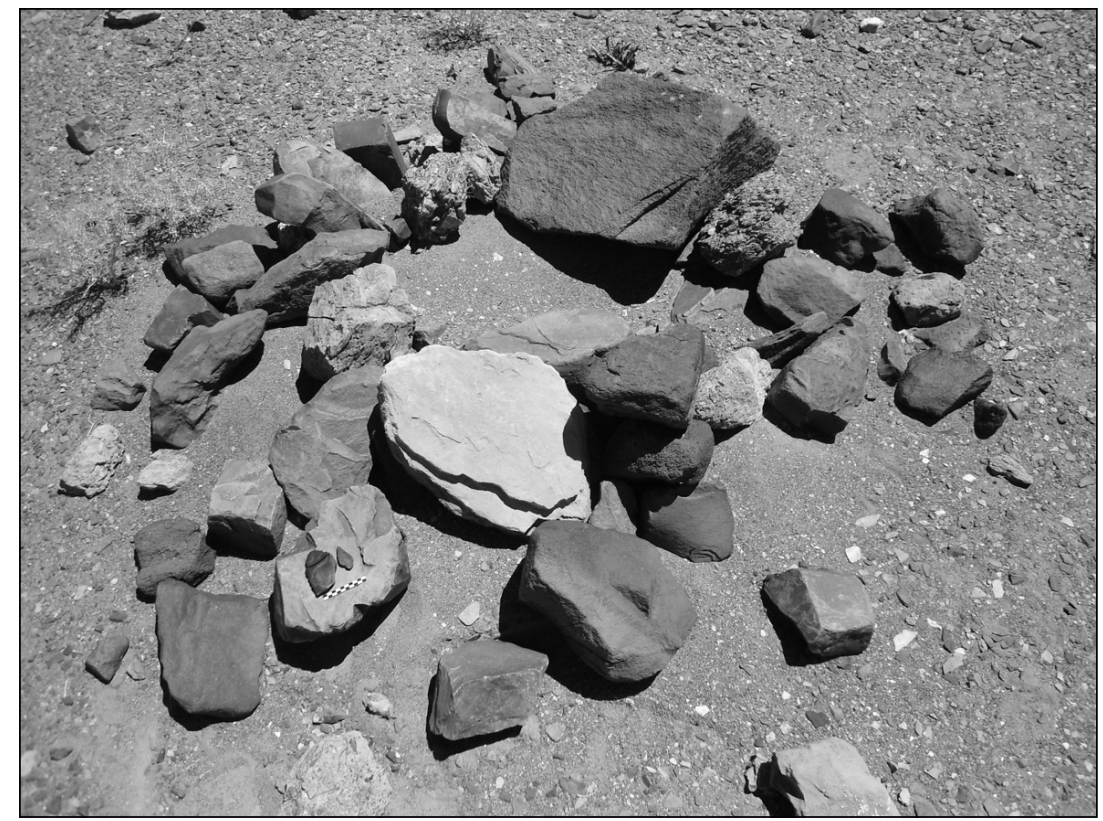

Figura 14. Estructura de habitación (posible sitio de pernocte) asociada a senderos en el sector de Los Negros. 


\section{* Movilidad y tráfico en ANTOfagasta de la} SIERRA

Los hallazgos que hemos venido realizando en los últimos años, tanto en estos espacios internodales como en el sector del volcán Galán (Martel 2014), nos permiten comenzar a discutir y repensar diversos aspectos vinculados a los procesos socioculturales ocurridos en ANS a lo largo de una porción de su historia, particularmente entre el Formativo y momentos históricos. Trataremos, entonces, de analizar la evidencia recuperada de manera integrada de forma tal que podamos comenzar a entender -o al menos, generar una propuesta sobre- el modo en que los grupos humanos que habitaron ANS se vincularon e interactuaron con las comunidades vecinas.

En primer lugar, es necesario recordar las características de las ocupaciones y otras evidencias recuperadas en el internodo del volcán Galán; un espacio no propicio para la instalación humana permanente y el cual debe atravesarse, desde ANS, para alcanzar los nodos del valle Calchaquí medio. Allí registramos cinco sitios asociados a una vía de circulación que cruza este espacio internodal por su extremo norte, en un sector conocido como Aguas Calientes. Estos comprenden: dos sitios de pernocte (campamentos), dos apachetas, un sitio de habitación (puesto de caza/pastoreo) y un sitio con arte rupestre. Los materiales recuperados en uno de los campamentos (sitio Aguas Calientes $-\mathrm{ACl}$ ), presentaban componentes cerámicos Ciénaga gris inciso, Yavi N/R y Yavi Inka, artefactos y desechos de talla lítica de vulcanita (variedad l, procedencia quebrada del río Las Pitas, ANS) y de obsidiana (procedencia fuente de Ona, Antofalla), y un endocarpo de Prunus sp. (durazno) (Martel 2014).

El puesto, sitio $\mathrm{AC}_{5},{ }^{5}$ si bien mostraba reocupaciones sub-actuales, permitió la recuperación de diversos materiales que dan cuenta también de ocupaciones sucesivas en el tiempo. Los componentes cerámicos comprenden fragmentos de cerámica Ciénaga gris pulido (Formativo), fragmentos Belén y Santa María (PDR), desechos de talla de vulcanitas y obsidianas, cerámica histórica, fragmentos de vidrio, latas de conserva y casquillos de proyectiles de armas de fuego (Figura 15).

5 El sitio $\mathrm{AC}_{5}$ (Aguas Calientes 5) fue hallado posteriormente a la publicación citada (Martel 2014), por lo tanto consignamos aquí sus coordenadas: S $25^{\circ} 49^{\prime} 32,45^{\prime \prime}, \mathrm{O} 66^{\circ} 55^{\prime} 27,69^{\prime \prime}, 4484 \mathrm{msnm}$.
Por su parte, el sitio con arte rupestre $\mathrm{AC}_{4}$, presenta una secuencia de producción de sus representaciones que se extiende cronológicamente, tal como en $\mathrm{ACl}_{1}$ y $\mathrm{AC}_{5}$, desde el Formativo hasta momentos históricos. En el conjunto rupestre se destacan, para momentos formativos, los motivos de camélidos, antropomorfos y antropomorfo con camélidos; para el PDR, motivo de caravana de llamas; para momentos históricos, motivo de caravana de equinos, escena de jinete arreando vacuno, jinetes, marcas de ganado, cruces cristianas y nombres.

Siguiendo a Nielsen (2006), esta evidencia -si bien escasa- nos presenta los dos tipos de ocupaciones esperables en un internodo: ocupaciones de tránsito $\left(\mathrm{ACl}, \mathrm{AC}_{4} \mathrm{y}\right.$ apachetas) y ocupaciones extractivas ( $\mathrm{AC}_{5}$ ). Estos tipos de ocupaciones responden a dos modalidades de tráfico que, a su vez, involucran formas distintas para la circulación de bienes y recursos. Nos referimos a lo que el autor citado define como tráfico especializado y tráfico incorporado, cuyas respectivas implicancias deben ser abordadas en el ámbito del tipo de relaciones entabladas entre las comunidades y/o colectivos sociales interactuantes. En este sentido, es sumamente interesante la coexistencia de los estilos Belén y Santa María en $\mathrm{AC}_{5}$, ya que muestra una asociación infrecuente a ambos lados del internodo, donde lo santamariano tiene un marcado predominio en los sitios del PDR del valle Calchaquí medio (Sprovieri 2011), mientras que lo Belén y otros estilos más característicos de los valles catamarqueños predominan en ANS (Olivera et al. 2008). Volveremos sobre este punto más adelante.

Por su parte, en el internodo El Peñón/Carachipampa, el registro muestra diferencias significativas que, en términos conductuales, permiten definir con mayor precisión el tipo de movilidad y las prácticas involucradas. En primer lugar, se registró y documentó una vía de circulación (sensu Pimentel 2013) concreta, conformada por numerosos senderos producidos a lo largo del tiempo por el frecuente transitar de animales y personas. Esta vía que, como dijimos anteriormente, representa un segmento de la ruta que permitió el tránsito entre ANS, el bolsón de Laguna Blanca y valles como El Bolsón, Hualfín y Belén, muestra un conjunto de rasgos que responden -tal como fueron descriptos más arriba- a una infraestructura ligada directamente a las prácticas de movilidad y logística del tráfico, en un rango temporal que excede lo prehispánico. 


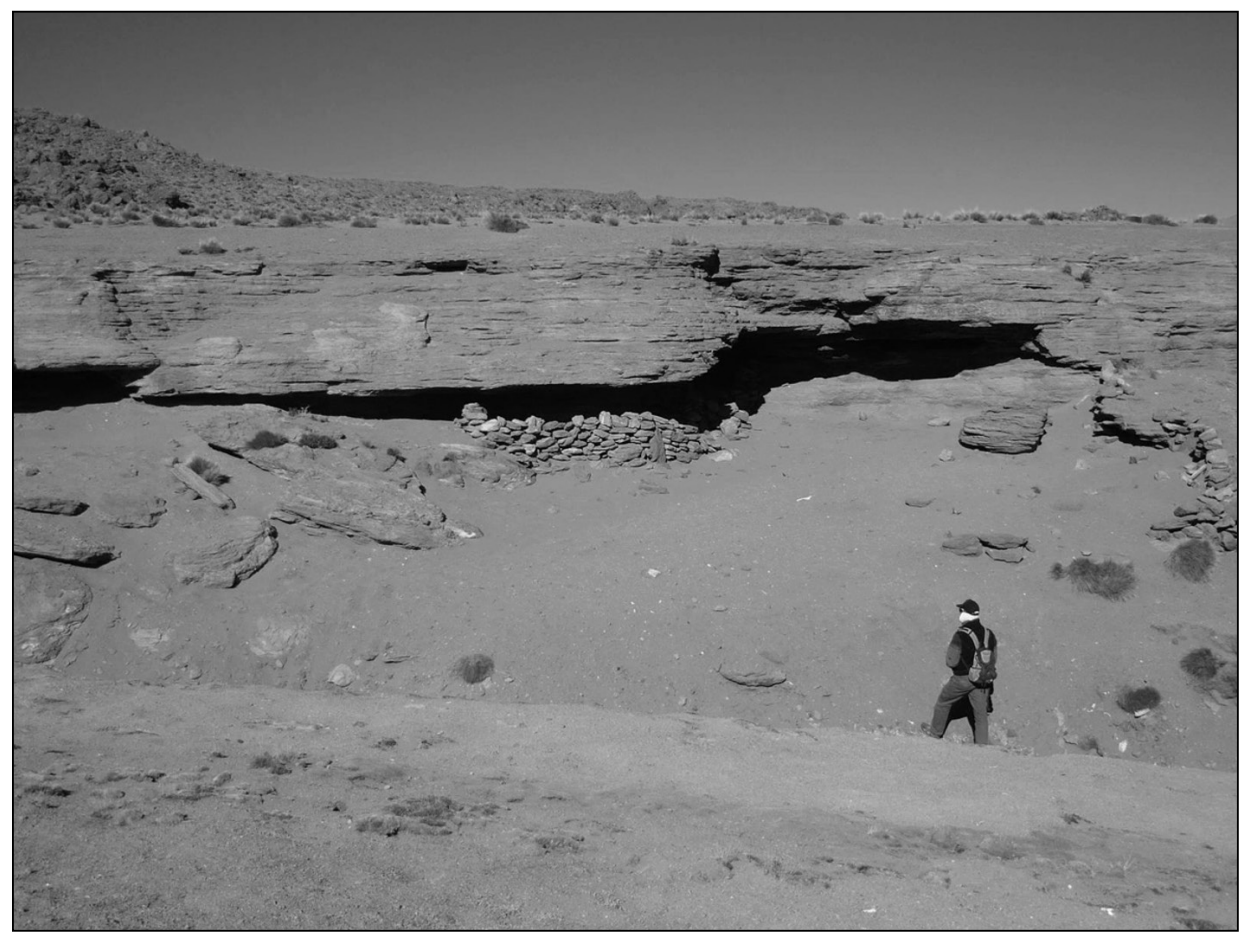

Figura 15. Sitio Aguas Calientes 5, internodo volcán Galán.

La variedad de sitios (rasgos y estructuras) asociados a los senderos que cruzan este espacio internodal, ponen de manifiesto un tipo de movilidad que asume las características esperables en el tráfico especializado (sensu Nielsen 2006). Estructuras de habitación de factura muy expeditiva (recintos pequeños y parapetos) y rasgos particulares vinculados a prácticas ceremoniales y/o de demarcación vial (acumulaciones circulares de rocas de distintos colores, mojones y el montículo ya mencionado), se suceden a lo largo del trayecto registrado y conforman -junto a los senderos- un contexto de tráfico propiamente tal.

En síntesis, podemos decir que los espacios internodales trabajados (volcán Galán y El Peñón/Carachipampa) presentan un registro arqueológico con similitudes y diferencias sumamente significativas -identidades diacríticas, sensu Berenguer (2004)-, que nos permiten conocer mayores detalles respecto de las relaciones establecidas entre las comunidades que habitaron ANS y sus vecinas de los nodos valliserranos. En primer lugar, el área internodal del volcán Galán nos muestra tanto ocupaciones de tránsito (sitios $\mathrm{AC}_{1}$ a $\mathrm{AC}_{4}$ ), vinculadas al tráfico especializado, como extractiva (sitio $\mathrm{AC}_{5}$ ), relacionada con un tráfico incorporado. Ahora bien, teniendo en cuenta la adscripción cronológica de los materiales registrados en ambos tipos de ocupaciones, surge una diferencia notable: mientras los componentes (sensu Nielsen 2011) cerámicos y rupestres de los sitios de tránsito - particularmente $\mathrm{AC}_{1}$ y $\mathrm{AC}_{4}$ - nos remiten a los Períodos Formativo, Inka e Histórico, el sitio AC5 -asociado a una ocupación extractiva- presenta componentes del Formativo, PDR e Histórico.

Por su parte, el área internodal de El Peñón/Carachipampa ofrece una vía de circulación con numerosos sitios asociados directamente a la misma, cuyas características materiales permiten definirlos como ocupaciones de tránsito, las que se habrían generado en el marco de prácticas de interacción del tipo de tráfico especializado. A su vez, los materiales recuperados definen componentes correspondientes a los Períodos Formativo, PDR e Histórico.

A continuación discutiremos los posibles contextos sociohistóricos que habrían propiciado los distintos modos de interacción registrados, y que involucran las relaciones sociales establecidas a lo largo del tiempo entre ANS y el valle Calchaquí medio, por un lado, y los valles catamarqueños, por el otro. 
La evidencia y contextos analizados hasta el momento, nos llevan a plantear algunas tendencias sincrónicas y diacrónicas respecto de la movilidad y modos de interacción entre las comunidades consideradas. Conviene recordar que por la escasez material característica que presentan los sitios en contextos de tráfico, este análisis toma como principal línea de evidencia el registro cerámico obtenido directamente en las vías de circulación estudiadas.

En primer lugar, los sitios con componentes y fechado Formativos comprenden ocupaciones de tránsito tanto en el internodo del volcán Galán (sitios $\mathrm{AC}_{1}$ y $\mathrm{AC}_{4}$ ) como en el de El Peñón/Carachipampa (sitios PChP 22, 43 y 44). Este hecho tiene una implicancia concreta y es que, durante el Formativo, se habría consolidado el tráfico especializado como una modalidad de interacción que permitió "el desplazamiento de bienes y personas de una región a otra mediante una secuencia de actividades organizadas enfunción de ese traslado, que se traduciría en testimonios arqueológicos de 'ocupaciones de tránsito' en el internodo"(Nielsen 2006: 48). A su vez, la asociación directa de los sitios a senderos producidos por el tránsito frecuente de animales, nos lleva a postular el uso de llamas como medio de transporte para la carga. No obstante, no descartamos la modalidad pedestre como otro mecanismo de interacción vigente en este período, sin embargo no contamos todavía con información contextual suficiente como para discriminar entre estas dos modalidades. Para finalizar, podemos decir que para el Formativo las comunidades que habitaron ANS habrían mantenido contactos intersocietales 'punto a punto' tanto hacia el este (valle Calchaquí medio) como hacia el sur (valles catamarqueños), sin aparentes restricciones en la circulación de la mayoría de los bienes y recursos movilizados entre estos nodos (Martel 2014, López Campeny et al. 2014, entre otros).

Las consideraciones realizadas pueden inscribirse dentro de lo que Trombold (1991) define como análisis micromorfológico de la red vial, lo cual involucra observaciones sobre los aspectos espaciales y formales de las vías de circulación, los diversos tipos de sitios asociados a éstas, los objetos movilizados, las conexiones con otros nodos y su adscripción cronológica (Pimentel 2013). Ahora bien, siguiendo a los autores citados, el paso complementario comprende el análisis macromorfológico, donde se aborda el tratamiento de la infraestructura de la red vial, estrategias de movilidad y prácticas asociadas, intensidad de uso y las relaciones intersocietales inferidas.

Al evaluar la evidencia correspondiente al Período Formativo desde la perspectiva del análisis macromorfológico, podemos observar que el internodo del volcán Galán registra ocupaciones que se ajustan a otra estrategia de movilidad. El sitio $\mathrm{AC}_{5}$, mencionado más arriba, se emplaza en el borde de una estrecha vega en las nacientes del río Aguas Calientes y se halla conformado por los restos (cimientos) de dos antiguos corrales asociados espacialmente a un posible puesto histórico o subactual, con abundante material prehispánico en superficie que, como dijimos anteriormente, se adscribe a distintas cronologías. Cabe destacar que el puesto está configurado por un muro de pirka seca que cierra la boca de una pequeña cueva bajo un antiguo nivel de vega. Si tenemos en cuenta la mayor inversión de energía en la infraestructura (corrales), disponibilidad de recursos (agua, pasto, refugio) y redundancia de ocupación, es altamente probable que el sitio haya funcionado a través del tiempo como lugar de habitación temporal para el desarrollo de otrotipo de actividades como la caza y/o pastoreo. Si bien es el único sitio de este tipo registrado hasta el momento en este internodo, la proximidad de las lagunas Diamante y Cavi, que brindan la posibilidad de aprovisionamiento de recursos como huevos de flamenco y materias primas líticas, nos permite generar expectativas sobre la ocurrencia de otras ocupaciones extractivas que habrían favorecido la interacción social en el marco de la modalidad de tráfico incorporado.

Si comparamos los registros de momentos formativos de ambos internodos, podemos observar diferencias en las dinámicas y en las intensidades de la interacción, las cuales sirven para comenzar a delinear la naturaleza de los vínculos que se establecieron entre los grupos puneños y sus vecinos. Hacia el este, hacia el valle Calchaquí medio, se articularon ambas modalidades de tráfico, sin embargo, el escaso número de sitios asociados a la vía de circulación hace suponer una baja a moderada intensidad de uso de esta ruta de interacción. Mientras tanto, hacia el sur, hacia los valles catamarqueños, habría dominado la modalidad de tráfico especializado, manifestándose 
notablemente su intensidad de uso en sitios como PChP 44 (montículo), cuyo desarrollo habría estado sujeto a la frecuencia y continuidad de los viajes. Creemos necesario aclarar que, debido a la profundidad temporal de uso de esta vía de circulación, decidimos no considerar los múltiples senderos que la conforman como un rasgo de intensidad de uso, ya que por el momento no nos es posible discriminar cuáles de estos senderos tendrían su origen en momentos Formativos.

Por su parte, la evidencia recuperada correspondiente al PDR muestra continuidades y rupturas respecto de los momentos previos. Considerando en primer lugar el sitio $\mathrm{ACl}$ (ocupación de tránsito) en el internodo del volcán Galán, resulta sumamente sugerente la presencia de componentes cerámicos de estilos no locales de finales del PDR (Yavi N/R) y del período siguiente (Yavi Inka N/A), y la ausencia de componentes cerámicos del PDR más característicos de la región como el Santa María del valle Calchaquí y el Belén de la puna y valles catamarqueños (Martel 2014). Sin embargo, en el sitio AC5 (ocupación extractiva), estos dos componentes se hallan presentes, resultando una asociación que es infrecuente a lo largo del PDR tanto en sitios del valle Calchaquí medio (predominio del Santa María) como en los de Antofagasta de la Sierra (predominio de cerámica Belén).

Respecto al internodo El Peñón/Carachipampa, cabe recordar que todos los sitios registrados corresponden a ocupaciones de tránsito, es decir, campamentos asociados directamente a los senderos. Hasta el momento, en solo dos de estos sitios hemos hallado materiales asignables al PDR que, para el caso del sitio PChP 46, comprende un componente cerámico Belén N/R. ${ }^{6}$ Es importante señalar, también, el alto porcentaje de estructuras o rasgos posiblemente vinculados a prácticas ceremoniales y/o con fines de señalización de la vía de circulación. Nuevamente, en estos casos, se presentan las mismas incertidumbres cronológicas, las cuales se resolverán a medida que avancen las investigaciones. De todos modos, estos sitios particulares, sí nos permiten avanzar con mayor solidez hacia una definición de la infraestructura vial en este sector de la puna.

6 No descartamos que un número mayor de sitios se adscriban a esta cronología, pero al no contar con registro de superficie de materiales diagnósticos, resulta difícil estimarlo. Se prevé revertir esta situación a partir de la implementación de sondeos, excavaciones y fechados en los próximos trabajos de campo.
En síntesis, la evidencia internodal disponible para el PDR nos muestra - hasta el momento- diferencias muy significativas en relación a las modalidades de tráfico que operaron, por un lado, entre el ANS y el valle Calchaquí medio, y entre ANS y los valles catamarqueños. Podríamos decir que durante este período las interacciones sociales entre las comunidades puneñas y las calchaquíes se habrían dado - mayormente- en el marco de una estrategia de tráfico incorporado. Mientras tanto, las interacciones hacia el sur, con los valles catamarqueños, se habrían mantenido desde la modalidad del tráfico especializado.

\section{* Discusión}

Sabemos que la información obtenida en los estudios internodales se constituye en un complemento necesario de aquella disponible en los nodos, ya que permite una aproximación a una dimensión poco considerada en los estudios de interacción y que involucra a los actores, prácticas y contextos relacionales que permiten, o dificultan, la circulación de bienes en el marco de tales interacciones (Nielsen 2006). Esto nos lleva a una pregunta ineludible: ¿qué perspectivas nos abren los datos recabados en los internodos trabajados en relación a lo que ya conocemos para la arqueología de Antofagasta de la Sierra? Si bien la evidencia recuperada cubre un amplio lapso, preferimos en esta oportunidad restringir nuestras interpretaciones a los períodos Formativo y PDR.

En primer término, de un modo general, el registro de ocupaciones de tránsito y extractivas en los espacios intenodales, asociadas a senderos caravaneros, nos permite plantear que los mecanismos de interacción social a mediana y larga distancia en momentos formativos, estuvieron basados tanto en el tráfico especializado como en el tráfico incorporado. En un sentido más particular, podemos decir que hacia el este, en la interacción con los nodos del valle Calchaquí medio, se habrían dado ambas modalidades de interacción, mientras hacia el sur, hacia los valles catamarqueños, habría prevalecido el tráfico especializado.

Como bien destacan distintos autores (Berenguer 2004; Nielsen 2006; Yacobaccio 2012; Pimentel 2013, entre otros), el material lítico (particularmente la obsidiana) y la cerámica en contextos de tráfico, facilitan perspectivas generales respecto de las redes de circulación, dirección 
de los movimientos y agentes involucrados. De igual modo, los artefactos y desechos de talla de obsidianas, vulcanitas y cuarcitas registrados en sitios de ambos internodos, dan cuenta de fuentes localizadas dentro de la microrregión de ANS o próximas a ésta (p.e. obsidiana de Ona), lo que nos permite pensar en los pastores locales como artífices primarios del tráfico entre ANS y los nodos valliserranos. Por su parte, podríamos decir que los componentes cerámicos identificados marcan, principalmente a través de la estilística Ciénaga, las ya consabidas interacciones con los valles catamarqueños. Sin embargo, respecto del material cerámico, creemos necesario realizar algunas consideraciones previas a cualquier posible interpretación. A saber:

1. En el sitio PChP22, sitio de pernocte asociado a la vía de circulación que cruza el internodo El Peñón/Carachipampa, se recuperaron varios fragmentos que corresponden a un mismo objeto, una jarra con decoración comparable con Condorhuasi-Río Diablo.

2. Esta vía de circulación es la que permite una conexión directa entre Antofagasta de la Sierra y el bolsón de Laguna Blanca, a través del Abra de Pasto Ventura.

3. En Laguna Blanca, durante el Formativo, en sitios como el de Aldea Piedra Negra, se consolidó una producción alfarera local que, en parte, reproduce patrones decorativos comparables con estilos valliserranos como Condorhuasi-Río Diablo, Ciénaga y Aguada (Espiro 2012).

Al tener en cuenta estos elementos, vemos que el registro internodal incorpora a la discusión arqueológica local un aspecto hasta ahora no considerado y que alude a los vínculos entre los grupos formativos antofagasteños con los de Laguna Blanca. Esto suscita numerosas interrogantes sobre las propuestas mayormente aceptadas respecto de los procesos sociales durante el primer milenio de la era en ANS, cuyos desarrollos habrían estado en gran parte influidos por la estabilidad de los vínculos establecidos con grupos de los valles de Hualfín y Abaucán, principalmente (Elías y Escola 2010; Olivera et al. 2008, entre otros). Sin embargo, la evidencia recuperada en esta ruta de tráfico nos permite ubicar a ANS dentro de una red de interacción que involucra otro centro de producción cerámica (Laguna Blanca) - no considerado hasta el momento-, y plantear así nuevas alternativas para la circulación de ciertos bienes, recursos y personas entre los nodos de la puna meridional, de los valles catamarqueños y de regiones vecinas.

Para finalizar, más allá de las modalidades de tráfico identificadas y teniendo en cuenta los registros arqueológicos de los nodos que estas rutas pusieron en contacto (valle Calchaquí medio, Laguna Blanca, valles catamarqueños), no observamos para momentos formativos situaciones de restricción para la circulación de ciertos ítems, como algunos tipos cerámicos (Ciénaga gris pulida/incisa/grabada, Saujil o Río Diablo) y obsidianas (principalmente variedad Ona). Podemos decir que nuestras observaciones encuentran correspondencia en los planteos de Yacobaccio (2012), respecto de las características del tráfico durante este período:

Durante el Formativo no hay evidencias que indiquen alguna especialización en los bienes que circularon, sino más bien lo contrario, ya que el registro arqueológico altoandino contiene una alta variabilidad de bienes originados en otras regiones. Por otra parte, si bien el tráfico durante este período no parece haber tenido la intensidad de momentos posteriores, fue muy regular en el tiempo como lo muestra la circulación de las obsidianas (op. cit.: 33).

Ahora bien, la evidencia internodal adscripta al PDR nos permitió identificar continuidades y cambios en relación con el período anterior. En primer lugar, el internodo El Peñón/Carachipampa muestra la continuidad del uso de una vía de circulación donde todos los sitios y rasgos registrados - hasta el momento- responden a ocupaciones de tránsito, confirmando la permanencia del tráfico especializado como la modalidad de interacción principal entre ANS y los valles catamarqueños.

Es relevante destacar que, en este caso, no solo el registro cerámico (Belén) y lítico (obsidiana y vulcanitas locales) se presentan como los indicadores más conspicuos de la interacción y el tráfico entre estos nodos, también resulta importante recordar el hallazgo de tarabitas o ganchos de atalaje en contextos del PDR de ANS (Raviña et al. 2007, Elías et al. 2015). Si bien la recuperación de estos artefactos corresponde a contextos mortuorios, es ampliamente aceptado su desempeño en el aparejo de sujeción de las cargas que transportan las llamas. Por su parte, siguiendo los trabajos citados, las materias primas utilizadas para la confección de las tarabitas de ANS, corresponden 
a especies comunes de los valles mesotermales (Larrea sp. y Prosopis sp.).

Otro indicador sumamente significativo comprende el hallazgo, en ANS, de un cuerpo femenino momificado en el Alero Punta de la Peña 4, con un fechado para el contexto de $960 \pm 40$ años AP (López Campeny 20062007), que habría sido transportado en condiciones de enfermedad e inmovilidad desde los valles mesotermales, un hecho que apunta a pensar que estas redes de tráfico pueden estar sostenidas por relaciones de parentesco, activas desde momentos tan antiguos, o más, como ca. 3600 AP (Martel y Aschero 2007).

Esta continuidad en la práctica del tráfico especializado, desde el Formativo al PDR, implicó necesariamente la existencia de una estructura que garantizó su continuidad en el plano social (perduración de un modo de vida pastoril como precondición para la formalización de redes caravaneras) y una organización política que posibilitó el intercambio (individuos especializados dentro de las comunidades pastoriles) (Yacobaccio 2012).

En este sentido, si tenemos en cuenta los indicadores mencionados (tarabitas y el cuerpo femenino), más el hecho de que la cerámica Belén es la que presenta mayor frecuencia en los contextos del PDR de ANS y que su presencia fue constatada en asociación directa a la vía de circulación, podemos asumir que la interacción entre las comunidades antofagasteñas y las de los valles catamarqueños se habría fundado no solo sobre vínculos meramente económicos y/o políticos, sino también a partir de relaciones sociales de carácter familiar o parentesco. Sin embargo, esta situación de continuidad en las interacciones sociales y en la circulación de bienes, recursos y personas durante el PDR, cambia notablemente cuando analizamos la evidencia recuperada en el internodo del volcán Galán, allí donde se disponen las vías de circulación que permitieron los contactos entre ANS y el valle Calchaquí medio.

Tal como habíamos adelantado en un trabajo anterior (Martel 2014), la ausencia en $\mathrm{AC} 1$ (campamento caravanero) de un componente cerámico que remita al PDR local nos condujo, necesariamente, a poner atención a lo que sucedía con los estilos cerámicos a ambos lados del internodo. Por un lado, Cigliano y Raffino (1975) obser- varon que la cerámica Belén, tan frecuente en ANS, sería intrusiva en el pukara de Tacuil, debido a su bajísima proporción en relación a otros estilos como el Santa María y el Churcal rojo pulido. Cabe recordar que la quebrada de Tacuil, donde se emplaza el pukara, fue una importante vía de circulación entre la puna meridional y el valle Calchaquí, y formó parte de la red vial que involucró al internodo del volcán Galán (Cremonte y Williams 2007; Sprovieri y Baldini 2007; Vitry 2007; Martel 2014). Por su parte, Sprovieri (2011), a partir de su investigación en diversos sitios emplazados en el valle Calchaquí medio (cuenca del río Molinos), plantea la existencia de un "mundo calchaquí" que habría sido poco receptivo respecto al ingreso de estilos cerámicos foráneos. Hacia el otro lado del internodo, en ANS, se presenta la situación contraria: predominio de cerámica Belén por sobre otros estilos (Olivera 1992; Olivera et al. 2008; Raffino y Cigliano 1973; Tarragó et al. 1997, entre otros).

Estos datos nos permiten postular que, durante el PDR, se dio algún tipo de restricción para la circulación de objetos cerámicos entre estos nodos, situación que se vería reflejada en el registro material de $\mathrm{ACl}$. Ahora bien, a 6,5 $\mathrm{km}$ hacia el oeste de $\mathrm{AC}_{1}$, el sitio $\mathrm{AC}_{5}$ (puesto de caza/ pastoreo, ocupación extractiva) mostraba en superficie la coexistencia de fragmentos Belén y Santa María que, como dijimos anteriormente, comprende una asociación infrecuente en ambos nodos.

Reconocemos que la evidencia disponible hasta el momento en este internodo es muy escasa y sería riesgoso hablar de tendencias. Sin embargo, estas diferencias contextuales entre $\mathrm{AC}_{1}$ y $\mathrm{AC}_{5}$, nos permiten formular la siguiente hipótesis: las interacciones sociales, durante el PDR, entre las comunidades de ANS y las del valle Calchaquí medio, se habrían dado a partir de contactos circunstanciales en el marco de prácticas de aprovisionamiento de diversos recursos y/o de pastoreo trashumante, propiciando situaciones de tráfico incorporado. Sin embargo, al analizar la información disponible para este período respecto de la distribución de algunas materias primas líticas, particularmente la obsidiana de Ona (Yacobaccio et al. 2002; Yacobaccio et al. 2004; Sprovieri y Baldini 2007; Chaparro 2009), vemos que su circulación entre ANS y el valle Calchaquí no habría estado sujeta a restricciones como en el caso de los objetos cerámicos. Por lo tanto, si volvemos a la cita de Yacobaccio (2012) 
transcripta más arriba, podemos decir que la circulación de obsidiana en el PDR fue posible desde la continuidad de una modalidad de tráfico especializado ya establecida durante el Formativo. Parafraseando a Sprovieri (2011), ese mundo calchaquí poco receptivo respecto al ingreso de estilos cerámicos foráneos, sí habría sido más permeable respecto al ingreso de obsidianas.

\section{* Algunas conclusiones y nuevas INTERROGANTES}

Desde una perspectiva histórico procesual, podemos decir que los grupos que habitaron Antofagasta de la Sierra habrían participado, durante el Formativo, en circuitos de interacción 'nodo a nodo' a partir de un tráfico especializado que permitió la circulación de diversos ítems tanto hacia los valles catamarqueños como hacia el valle Calchaquí. Tal situación parece modificarse hacia el PDR, donde el registro sugiere una restricción en la circulación de los objetos cerámicos entre ANS y el valle Calchaquí. Todo indica que la evidencia recuperada responde a las propuestas originales de Núñez y Dillehay (1995) respecto a la disminución, en el PDR, de las distancias recorridas en los circuitos de tráfico caravanero, producto de las nuevas configuraciones sociopolíticas, los procesos de territorialización y la instalación de un contexto de beligerancia a escala macrorregional (Aschero 2000; Berenguer 2004; Nielsen 2007; Yacobaccio 2012, entre otros).

Sin embargo, si analizamos la cuestión del tráfico $-y$ las distancias de los circuitos- desde la perspectiva de la circulación de las obsidianas, la imagen que obtenemos de las redes de interacción es una más parecida a las Formativas que a aquellas más restringidas del PDR. Este fenómeno también fue observado por otros investigadores, quienes propusieron diversas aproximaciones para la circulación y tráfico de obsidianas a mediana y larga distancia. Por ejemplo, Yacobaccio (2012) sostiene que la amplia circulación de obsidianas durante el Formativo obedeció a mecanismos de interacción del tipo de tráfico especializado, ya que la irregularidad y circunstancialidad del tráfico incorporado no habría sido suficiente para dar cuenta de tales distancias. Propuesta a la que adherimos teniendo en cuenta la evidencia formativa presentada en este trabajo.
Por otra parte, para Elías y Escola (2008), el tráfico incorporado sí habría sido un mecanismo eficaz para la circulación de obsidianas en el conflictivo escenario del PDR, a partir de su articulación con otras redes menores con las que terminaron configurando un entramado mayor. En ese sentido, las autoras no descartan mecanismos de interacción de mayor distancia a partir de un tráfico especializado promovido por grupos con acceso directo a las fuentes de obsidiana, discutiendo así los alcances restrictivos que la territorialidad y beligerancia, que caracterizaron al período, habrían impuesto al desplazamiento de bienes, personas y animales. La evidencia disponible, para el PDR, en los internodos trabajados, refleja situaciones contextuales que bien podrían enmarcarse dentro de estas propuestas.

Si nos ajustamos al título de este trabajo,"Tráfico y movilidad caravanera en la puna catamarqueña. Una mirada internodal", la evidencia registrada en los espacios analizados es contundente. Aquellas interacciones e intercambios que nos anticipa el arte rupestre de caravanas y los recursos y artefactos foráneos, tan presentes y frecuentes en los sitios de Antofagasta de la Sierra, se materializa ahora en la configuración de una red vial que pone a nuestro alcance los diversos elementos que definen la materialidad del tráfico, entendiendo por materialidad ese mundo de objetos que actúa como medio para la constitución social del individuo y su comunidad (Preucel 2006). Los senderos que surcan estos amplios y rigurosos espacios, los campamentos y sitios ceremoniales, nos muestran el afuera de un mundo pastoril que definió un modo concreto de habitar la puna y que encontró en las distintas formas de interacción los argumentos para negociar y discutir, a) el poder, b) la autonomía en la toma de decisiones, y/o c) el establecimiento de alianzas en función de las contingencias sociales, políticas, económicas y culturales que trajo aparejado el tránsito desde el Período Formativo al Período de Desarrollos Regionales.

Agradecimientos A Carlos Aschero por apoyar e incentivar estas investigaciones. A Gonzalo Pimentel, Axel Nielsen y José Berenguer por el continuo intercambio de opiniones que ayudaron significativamente a este trabajo. A Mariano Corbalán, Verónica Puente y Valeria Espiro por su valiosa asistencia en la resolución de dudas sobre cerámicas. A Federico Bobillo por su 
colaboración en terreno y por su apoyo, junto a Shilo Hocsman, en los análisis líticos. A Pilar Babot por su ayuda en las consultas arqueobotánicas. A los revisores externos por sus oportunas y constructivas observa- ciones. Sin embargo, todo lo que aquí expresamos es de nuestra exclusiva responsabilidad. Este trabajo fue realizado en el marco del proyecto PIP-CONICET 464, dirigido por el Lic. Carlos Aschero.

\section{$\leftarrow$ RefERENCIAs citadas}

AMBROSETTI, J. B. 1904. Apuntes sobre la arqueología de la Puna de Atacama. Revista del Museo de La Plata, tomo XII: 3-30.

ASCHERO, C. 1988. De punta a punta: producción, mantenimiento y diseño de puntas de proyectil precerámicas de la Puna Argentina. Actas del IX Congreso Nacional de Arqueología Argentina, pp. 219-229, Buenos Aires.

ASCHERO, C. 2000. Figuras humanas, camélidos y espacios en la interacción circumpuneña. En Arte en las rocas. Arte rupestre, menhires y piedras de colores en la Argentina, M. Podestá y M. de Hoyos (Eds.), pp. 17-44. Sociedad Argentina de Antropología y Asociación Amigos del INAPL, Buenos Aires.

ASCHERO, C. 2007. Iconos, huancas y complejidad en la Puna sur argentina. EnProducción y circulación prehispánica de bienes en el sur andino, A. Nielsen et al. (Comps.), pp. 135-165. Editorial Brujas, Córdoba.

ASCHERO, C. 2010. Arqueologías de Puna y Patagonia centromeridional: comentarios generales y aporte al estudio de los cazadores-recolectores puneños en los proyectos dirigidos desde el IAM (1991-2009). En Rastros en el camino... Trayectos e identidades de una institución. Homenaje a los 80 años del IAM-UNT, P. Arenas, C. Aschero y C. Taboada (Eds.), pp. 257-293. EDUNT Editorial, San Miguel de Tucumán.

ASCHERO, C., R. ZURITA, M. G. COLANERI y A. TOSELLI. 2002. El bebé de la Peña. Actas XIII Congreso Nacional de Arqueología Argentina, pp. 329-336. Universidad Nacional de Córdoba, Córdoba.

BABOT, M. P. 2009. La cocina, el taller y el ritual: explorando las trayectorias del procesamiento vegetal en el Noroeste argentino. Darwiniana 47(1): 7-30.

BERENGUER, J. 2004. Caravanas, interacción y cambio en el desierto de Atacama. Sirawi Ediciones, Santiago.

BERENGUER, J. y G. PIMENTEL. 2010. Arqueología de los “espacios vacíos": una aproximación internodal a las relaciones intersocietales. Actas del XVII Congreso Nacional de Arqueología Chilena, tomo 2, pp. 1305-1308. Universidad Austral de Chile. Ediciones Kultrun, Valdivia.
BOMAN, E. 1991 [1908]. Antigüedades de la región andina de la República Argentina y el desierto de Atacama, tomos 1 y 2. Universidad Nacional de Jujuy, Jujuy.

CIGLIANO, E. y R. RAFFINO. 1975. Arqueología en la vertiente occidental del valle Calchaquí medio. Relaciones de la Sociedad Argentina de Antropología IX (N. S.): 47-56.

CREMONTE, B. y V. WILLIAMS. 2007. La construcción social del paisaje durante la dominación Inka en el Noroeste argentino. En Procesos sociales prehispánicos en el sur andino. La vivienda, la comunidad y el territorio, A. Nielsen et al. (Comps.), pp. 207-236. Editorial Brujas, Córdoba.

CHAPARRO, M. G. 2009. El manejo de los recursos líticos en el pasado. Sociedades pre-estatales y estatales en el área valliserrana del Noroeste argentino $(1000-1536$ DC). Tesis de Doctorado inédita. Facultad de Filosofía y Letras, Universidad de Buenos Aires, Buenos Aires.

ELÍAS, A., B. MARCONETTO y D. OLIVERA. 2015. Aportes al registro de tarabitas en Antofagasta de la Sierra. Revista de Antropología del Museo de Entre Ríos 1(1): 99-102.

ELÍAS, A. y P. ESCOLA, 2010. Viejos y nuevos horizontes: obsidianas entre las sociedades agrícolas-pastoriles del período Tardío en Antofagasta de la Sierra (provincia de Catamarca, Puna Meridional Argentina). Revista Española de Antropología Americana 40/2: 9-29.

ESCOLA, P. 2007. Obsidianas en contexto: tráfico de bienes, lazos sociales y algo más. En Sociedades precolombinas surandinas: Temporalidad, interacción y dinámica cultural del NOA en el ámbito de los Andes Centro-Sur, V. Williams, B. Ventura, A. Callegari y H. Yacobaccio (Eds.), pp. 73-87. Edición de Autor, Buenos Aires.

ESCOLA, P., S. HOCSMAN y M. P. BABOT. 2013. Entre las residencias y los campos de cultivo. Aportes de los cuchillos/raederas de módulo grandísimo a la cuestión del laboreo agrícola en Antofagasta de la Sierra (Puna de Catamarca) durante el primer milenio d.C. Relaciones de la Sociedad Argentina de Antropología XXXVIII(1): 83-110. 
ESPIRO, V. 2008. Características del proceso de manufactura de las alfarerías de la aldea Piedra Negra, correspondientes al primer milenio de nuestra era, Distrito Laguna Blanca, Departamento Belén, Provincia de Catamarca. La Zaranda de Ideas 4: 9-25.

ESPIRO, V. 2012. Del hacer de las ollas. La producción cerámica en una base residencial de la aldea Piedra Negra (I milenio DC). Laguna Blanca. Estudios Atacameños 43: 53-70.

KORSTANJE, M. A. 2004. Microfossils in camelid dung: taphonomic considerations for the archaeological study of agriculture and pastoralism. En Biosphere to Lithosphere. New studies in vertebrate taphonomy, Terry O'Connor (Ed.), pp. 69-77. Oxbow Books, Oxford.

LÓPEZ CAMPENY, S. 2006-2007. El poder de torcer, anudar y trenzar a través de los siglos. Textiles y ritual funerario en la Puna Meridional Argentina. Cuadernos del Instituto Nacional de Antropología y Pensamiento Latinoamericano 21: 143-155.

LÓPEZ CAMPENY, S. 2008. Portar, contener y vestir: Tres líneas de evidencias para la discusión de redes sociales tramadas a distancia. En Jornadas de Arqueología del Área Puneña de los Andes Centro-Sur. Tendencias, Variabilidad y Dinámicas de Cambio (ca. 11.000-1000 AP), S. Hocsman, M. Babot y J. Martínez (Comps.), pp. 91-94. EDUNT, Tucumán.

LÓPEZ CAMPENY, S. 2010. De un hogar en la Puna... Relatos de idas y vueltas. En El hábitat prehispánico. Arqueología de la arquitectura y de la construcción del espacio organizado, M. E. Albeck, C. Scattolin y M. A. Korstanje (Eds.), pp. 215-242. Editorial de la Universidad Nacional de Jujuy, Jujuy.

LÓPEZ CAMPENY, S., A. ROMANO, M. F. RODRÍGUEZ, A. MARTEL y M. CORBALÁN. 2014. De aquí y de allá: análisis integral de un contexto funerario. Acerca de vínculos e interacción social entre Puna meridional y Tierras Bajas orientales. Intersecciones en Antropología 15: 201-218.

MARTEL, A. 2010. Arte rupestre de pastores y caravaneros. Estudio contextual de las representaciones rupestres durante el periodo Agroalfarero Tardio (900-1480 DC) en el Noroeste argentino. Tesis Doctoral inédita. Facultad de Filosofía y Letras, Universidad Nacional de Buenos Aires, Buenos Aires.

MARTEL, A. 2014. Aguas Calientes. Evidencias directas de tráfico caravanero entre la Puna meridional y el Valle Calchaquí. Estudios Sociales del NOA 13: 103-124.

MARTEL, A. y C. ASCHERO. 2007. Pastores en acción: Imposición iconográfica vs. autonomía temática. En Producción y circulación prehispánicas de bienes en el sur andino, A. Nielsen et al. (Comps.), pp. 329-349. Editorial Brujas, Córdoba.
MARTÍNEZ, J., C. ASCHERO, J. POWELL y P. TCHILINGUIRIAN. 2007. A gap between extinct Pleistocene megafaunal remains and Holocene burial contexts at archaeological sites in the southern argentinian Puna. Current Research in the Pleistocene 24: 60-62.

NIELSEN, A. 1997-1988. Tráfico de caravanas en el Sur de Bolivia: Observaciones etnográficas e implicancias arqueológicas. Relaciones de la Sociedad Argentina de Antropología XXII-XXIII: 139-178.

NIELSEN, A. 2000. Andean caravans: anethno archaeology. Tesis Doctoral inédita. University of Arizona, Tucson.

NIELSEN, A. 2003. Por las rutas del Zenta: evidencias directas del tráfico prehispánico entre Humahuaca y las Yungas. En La mitad verde del mundo andino. Investigaciones arqueológicas en la vertiente oriental de los Andes y las tierras bajas de Bolivia y Argentina, G. Ortiz y B. Ventura (Eds.), pp. 261-284. EdiUnju, Jujuy.

NIELSEN, A. 2006. Estudios internodales e interacción interregional en los Andes circumpuneños: teoría, método y ejemplos de aplicación. En Esferas de interacción prehistóricas y fronteras nacionales modernas: los Andes surcentrales, H. Lechtman (Ed.), pp. 29-69. IEP-IAR, Lima.

NIELSEN, A. 2007. Armas significantes: tramas culturales, guerra y cambio social en el Sur andino prehispánico. Boletín del Museo Chileno de Arte Precolombino 12(1): 9-41.

NIELSEN, A. 2011. El tráfico de caravanas entre Lípez y Atacama visto desde la cordillera Occidental. En En ruta. Arqueología, Historia y Etnografía del tráfico sur andino, L. Núñez y A. Nielsen (Eds.), pp. 83-110. Encuentro Grupo Editor, Córdoba.

NÚÑEZ, L. y T. DILLEHAY. 1995. Movilidad giratoria, armonía social $y$ desarrollo en los Andes Meridionales: Patrones de tráfico e interacción económica. Universidad Católica del Norte, Antofagasta.

OLIVERA, D. 1992. Tecnología y Estrategias de Adaptación en el Formativo (Agroalfarero Temprano) de la Puna Meridional Argentina. Un Caso de Estudio: Antofagasta de la Sierra (Pcia. de Catamarca, R.A.). Tesis Doctoral inédita. Facultad de Ciencias Naturales, Universidad Nacional de La Plata, La Plata.

OLIVERA, D. 2006. Recursos bióticos y subsistencia en sociedades agropastoriles de la Puna meridional argentina. Comechingonia 9: 21-56.

OLIVERA, D., A. ELÍAS, P. SALMINCI, P. TCHILINGUIRIAN, L. GRANA, J. GRANT y P. MIRANDA. 2008. Nuevas evidencias del proceso sociocultural en Antofagasta de la Sierra. Informe de campaña año 2007. La Zaranda de Ideas 4: 99-119. 
PIMENTEL, G. 2009. Las huacas del tráfico. Arquitectura ceremonial en rutas prehispánicas del desierto de Atacama. Boletín del Museo Chileno de Arte Precolombino 14(2): 9-38.

PIMENTEL, G. 2013. Redes viales prehispánicas en el Desierto de Atacama: viajeros, movilidad e intercambio. Tesis Doctoral inédita. Universidad Católica del Norte, Instituto de Investigaciones Arqueológicas y Museo 'R. P. Gustavo Le Paige', San Pedro de Atacama.

PODESTÁ, M. y D. OLIVERA. 2006. El contexto ecológico y económico del arte rupestre en la arqueología de la Puna Meridional Argentina. En Kay Pacha. Cultivating Earth and Water in the Andes, P. Dransart (Ed.), pp. 137-149. BAR International Series 1478. Archaeopress, Oxford.

PREUCEL, R. 2006. Archaeological Semiotics. Blackwell Publishing, Malden.

RAFFINO, R. y E. CIGLIANO. 1973. La Alumbrera: Antofagasta de la Sierra. Un modelo de ecología cultural prehispánica. Relaciones de la Sociedad Argentina de Antropología VII (N. S.): 241-258.

RAVIÑA, M. G., A. M. FERNÁNDEZ y A. CAPPARELLI. 2007. La relación de las tarabitas, horquetas o ganchos de atalaje con el tráfico de bienes en momentos tardíos prehispánicos. Estudios Atacameños 33: 87-104.

RODRÍGUEZ, M. F. 1999. Arqueobotánica de Quebrada Seca 3 (Puna Meridional Argentina): Especies vegetales utilizadas en la confección de artefactos durante el Arcaico. Relaciones de la Sociedad Argentina de Antropología XXIV:159-184.

RODRÍGUEZ, M. F. 2005. Human evidence during middle Holocene in the Salty Argentine Puna. Archaeobotanical record analyzes. Quaternary International 132(1): 15-22.

RODRÍGUEZ, M. F. y C. ASCHERO. 2005. Acrocomia chunta (Arecaceae). Raw material for cord making in the Argentinean Puna. Journal of Archaeological Science 32(10): 1534-1542.

RODRÍGUEZ, M. F. y J. MARTÍNEZ. 20o1. Especies vegetales como recursos arqueológicos en el ámbito puneño. Asociación Paleontológica Argentina 8: 139-145.

SALMINCI, P. 2015. Simetría y diferenciación espacial. Los edificios de La Alumbrera, Antofagasta de la Sierra. Arqueología 21(1): 89-114.
SOMONTE, C. y L. COHEN. 2006. Caracterización de los conjuntos líticos del sitio agropastoril Punta de La Peña 9-III: Un aporte a la dinámica ocupacional puneña (Antofagasta de la Sierra, Catamarca, Argentina). Werken 9: 135-158.

SPROVIERI, M., 2011. El mundo en movimiento: circulación de bienes, recursos e ideas en el Valle Calchaquí (Salta). Una visión desde La Paya (Resumen de Tesis). Arqueología 17: 339-343.

SPROVIERI, M. y L. BALDINI. 2007. Aproximación a la producción lítica en sociedades tardías. El caso de Molinos I, Valle Calchaquí central (Salta). Intersecciones en Antropología 8: 135-147.

TARRAGÓ, M., L. GONZÁLEZ y J. NASTRI. 1997. Las interacciones prehispánicas a través del estilo: el caso de la iconografía santamariana. Estudios Atacameños 14: 223-242.

TROMBOLD, C. 1991. An introduction to the study of ancient New World road networks. En Ancient road networks and settlement hierarchies in the new world, C. Trombold (Ed.), pp.1-9. Cambridge University Press, Cambridge.

VITRY, Ch. 2002. Apachetas y mojones, marcadores espaciales del paisaje prehispánico. Revista Escuela de Historia 1(1): 179-191.

VITRY, Ch. 2007. La ruta de Diego de Almagro en el territorio argentino: un aporte desde la perspectiva de los caminos prehispánicos. Revista Escuela de Historia 6: 325-351.

WEISSER, V. 1923. Diarios y libretas de campo de la V Expedición Benjamín Muniz Barreto. Departamento de Arqueología (Ms.). Museo de La Plata, La Plata.

YACOBACCIO, H. 2012. Intercambio y caravanas de llamas en el Sur andino. Comechingonia 16: 13-33.

YACOBACCIO, H., P. ESCOLA, M. LAZZARI y F. PEREYRA. 2002. Long distance obsidian traffic in northwestern Argentina. En Geochemical evidence for long-distance exchange, M. Glascock (Ed.), pp. 167-203. Bergin and Garvey, Westport.

YACOBACCIO, H., P. ESCOLA, F. PEREYRA, M. LAZZARI y M. GLASCOCK. 2004. Quest for ancient routes: Obsidian sourcing research in northwestern Argentina. Journal of Archaeological Science 31: 193-204. 